Article

\title{
Surface Persistence of Trace Level Deposits of Highly Energetic Materials
}

\author{
Leonardo C. Pacheco-Londoño 1,2,*隹, José L. Ruiz-Caballero 1,3,4 ${ }^{\mathbb{D}}$, Michael L. Ramírez-Cedeño ${ }^{1}$, \\ Ricardo Infante-Castillo ${ }^{5}(0)$, Nataly J. Gálan-Freyle ${ }^{1,2}\left(\mathbb{D}\right.$ and Samuel P. Hernández-Rivera ${ }^{1, *(1)}$ \\ 1 R3-C Research and Education Component of ALERT DHS Center of Excellence for Explosives Research, \\ Department of Chemistry, University of Puerto Rico, Mayaguez Campus, Mayaguez, PR 00681, USA; \\ jose.ruiz9@upr.edu (J.L.R.-C.); michael.l.ramirez@gmail.com (M.L.R.-C.); \\ nataly.galan@unisimonbolivar.edu.co (N.J.G.-F.) \\ 2 School of Basic and Biomedical Sciences, Universidad Simón Bolívar, Barranquilla, \\ 080020 Atlantico, Colombia \\ 3 Joseph Smith \& Sons Inc., Capitol Heights, MD 20743, USA \\ 4 Department of Chemistry and Biochemistry, George Mason University, Fairfax, VA 22030, USA \\ 5 Department of Physics-Chemistry, University of Puerto Rico, Arecibo, PR 00614, USA; ricinfante@gmail.com \\ * Correspondence: leonardo.pacheco@unisimonbolivar.edu.co or pacheco.londono@gmail.com (L.C.P.-L.); \\ samuel.hernandez3@upr.edu (S.P.H.-R.); Tel.: +57-3046489549 (L.C.P.-L.)
}

Received: 23 August 2019; Accepted: 16 September 2019; Published: 26 September 2019

check for updates

\begin{abstract}
In the fields of Security and Defense, explosive traces must be analyzed at the sites of the terrorist events. The persistence on surfaces of these traces depends on the sublimation processes and the interactions with the surfaces. This study presents evidence that the sublimation process of these traces on stainless steel (SS) surfaces is very different than in bulk quantities. The enthalpies of sublimation of traces of four highly energetic materials: triacetone triperoxide (TATP), 2,4-dinitrotoluene (DNT), 2,4,6-trinitrotoluene (TNT), and 1,3,5- trinitrohexahydro-s-triazine (RDX) deposited on SS substrates were determined by optical fiber coupled-grazing angle probe Fourier Transform Infrared (FTIR) Spectroscopy. These were compared with enthalpies of sublimation determined by thermal gravimetric analysis for bulk amounts and differences between them were found. The sublimation enthalpy of RDX was very different for traces than for bulk quantities, attributed to two main factors. First, the beta-RDX phase was present at trace levels, unlike the case of bulk amounts which consisted only of the alpha-RDX phase. Second, an interaction between the RDX and SS was found. This interaction energy was determined using grazing angle FTIR microscopy. In the case of DNT and TNT, bulk and traces enthalpies were statistically similar, but it is evidenced that at the level of traces a metastable phase was observed. Finally, for TATP the enthalpies were statistically identical, but a non-linear behavior and a change of heat capacity values different from zero was found for both trace and bulk phases.
\end{abstract}

Keywords: sublimation; explosive; FTIR; thermogravimetric analysis; grazing angle

\section{Introduction}

The residence time of a highly energetic material (HEM) on a surface can be defined as the time that the material persists on the surface after its deposition. The concept is essential for the development of samples and standards for trace detection systems [1-12]. Aside from adhesion considerations, the residence time mainly depends on the vapor pressure of the compound and surface-HEM interactions. The vapor pressure of a HEM and its interaction with any given surface can be characterized in terms of the desorption energy and the sublimation enthalpy. The desorption energy $\left(\Delta_{\text {des }} U\right)$ can be defined as the change in energy when a substance adsorbed on a surface is 
desorbed. The desorption of an adsorbed molecule is an elemental surface kinetics process and is a measure of the strength of the interaction between the surface and the adsorbed species [13]. The enthalpy of sublimation $\left(\Delta_{s u b} H\right)$ is the energy change when a compound changes from the solid phase to the gas phase. These enthalpies are present for a solid deposited on a surface. If the solid-surface interaction is small, $\Delta_{d e s} U$ is insignificant, and the sublimation is the main phenomenon. There are two general ways of calculating $\Delta_{s u b} H$, i.e., directly and indirectly. In the direct method, a calorimeter is used to measure the heat exchanged during the change of phase. In the indirect determination, the vapor pressure, or a proportional parameter thereof, is measured at different temperatures and the enthalpy can be calculated by use of the Clausius-Clapeyron equation [14-16]. Various approaches can be taken to characterize the vapor pressures of materials. These include direct measurements with a manometer [17], the use of mass spectrometry to monitor the gas phase concentration of the species, measurement of sample volatilization by vacuum diffusion [18] (using a Knudsen cell), and boiling point determination under different pressures by differential scanning calorimetry. Several studies have reported that thermogravimetric analysis (TGA) is a rapid and convenient method to obtain vapor pressure curves and the enthalpies of sublimation and vaporization of volatile materials, such as active pharmaceutical ingredients and HEMs with different vapor pressures [19-22]. Sublimation enthalpies can also be measured by spectroscopic methods such as fluorescence. For example, Stefanov et al. used fluorescence monitoring to estimate the sublimation enthalpies of tetraphenylporphyrin, porphine, and Nile red, a fluorescent intracellular dye [23]. In the present study, the sublimation enthalpies of triacetone triperoxide (TATP), 2,4-dinitrotoluene (DNT), 2,4,6-trinitrotoluene (TNT), and 1,3,5-trinitrohexahydro-s-triazine (RDX) deposits on stainless steel (SS) substrates were obtained from mid-infrared (MIR) grazing angle probe fiber-optic (GAP)-coupled FTIR spectroscopy measurements, which were performed under isothermal conditions at different temperatures. The results were then compared with those obtained for the bulk samples by TGA. Furthermore, $\Delta_{\text {des }} U$ for RDX on SS was obtained by thermal desorption spectroscopy (TDS) measurements using grazing-angle objective (GAO) FTIR microspectroscopy.

\section{Materials and Methods}

\subsection{Reagents}

The reagents used in this research were acetone $\left(\mathrm{CH}_{3} \mathrm{COCH}_{3}, 98 \%\right.$, Aldrich-Sigma Chemical Co., Milwaukee, WI, USA), isopropanol (99\%, Aldrich-Sigma, Saint Louis, MO, USA), hydrogen peroxide $\left(\mathrm{H}_{2} \mathrm{O}_{2}, 50 \%\right.$ in water, Aldrich-Sigma), hydrochloric acid ( $\mathrm{HCl}, 12 \mathrm{M}$, Merck, VWR, Inc., West Chester, PA, USA), sulfuric acid $\left(\mathrm{H}_{2} \mathrm{SO}_{4}, 18 \mathrm{M}\right.$, Merck, VWR), and dichloromethane $\left(\mathrm{CH}_{2} \mathrm{Cl}_{2}\right.$, Aldrich-Sigma). Standard solutions of RDX (1000 ppm in acetonitrile, GC/MS primary standards grade) were obtained from Restek Corp. (Bellefonte, PA, USA) and from Chem Service, Inc. (West Chester, PA, USA). Crystalline samples of 2,4-DNT and TNT were purchased Chem Service, Inc.

\subsection{Synthesis of TATP}

Caution: TATP is a primary explosive sensitive to impact, friction, electric discharge, and flame. The synthesis and handling of TATP are dangerous operations that require safety precautions. TATP could not be purchased from chemical suppliers at the level of purity and amount required for the study. Samples were prepared in small quantities as needed without storing due to the high thermal instability of this powerful and highly unstable explosive. For the synthesis, $1 \mathrm{~mL}$ of $0.01 \mathrm{M}$ $\mathrm{HCl}$ was mixed with $3 \mathrm{~mL}$ of peroxide, $2 \mathrm{~mL}$ of acetone, and $4 \mathrm{~mL}$ water. Crystals formed after $5 \mathrm{~h}$. The crystals were then filtered and washed, first with cold distilled water and next with a small amount of cold methanol. The solid was then recrystallized from methanol. 


\subsection{Instrumentation}

A grazing angle probe (GAP; Remspec Corp., Charlton, MA, USA) interfaced to a Vector-22 FTIR interferometer (Bruker Optics, Billerica, MA, USA) equipped with an external mercury cadmium telluride (MCT) MIR detector was used for the spectroscopic monitoring of analytes deposited on the test surfaces. The GAP head uses carefully aligned mirrors to deliver a MIR beam to the sample surface at the grazing angle (approximately $80^{\circ}$ from the surface normal) [24]. The spectrometer was coupled to the GAP by a MIR-transmitting fiber-optic cable $[25,26]$. The $1.5 \mathrm{~m}$ fiber was made from a chalcogenide (As-Se-Te) optical glass bundle that transmits throughout the MIR region except for a strong $\mathrm{H}-\mathrm{Se}$ absorbance band at $2200 \mathrm{~cm}^{-1}$. The GAP beam was focused on a solid surface that was in thermal contact with an aluminum block equipped with a temperature controlled water bath. Samples were placed on SS plates on top of this surface. The experimental setup is illustrated in Figure 1.

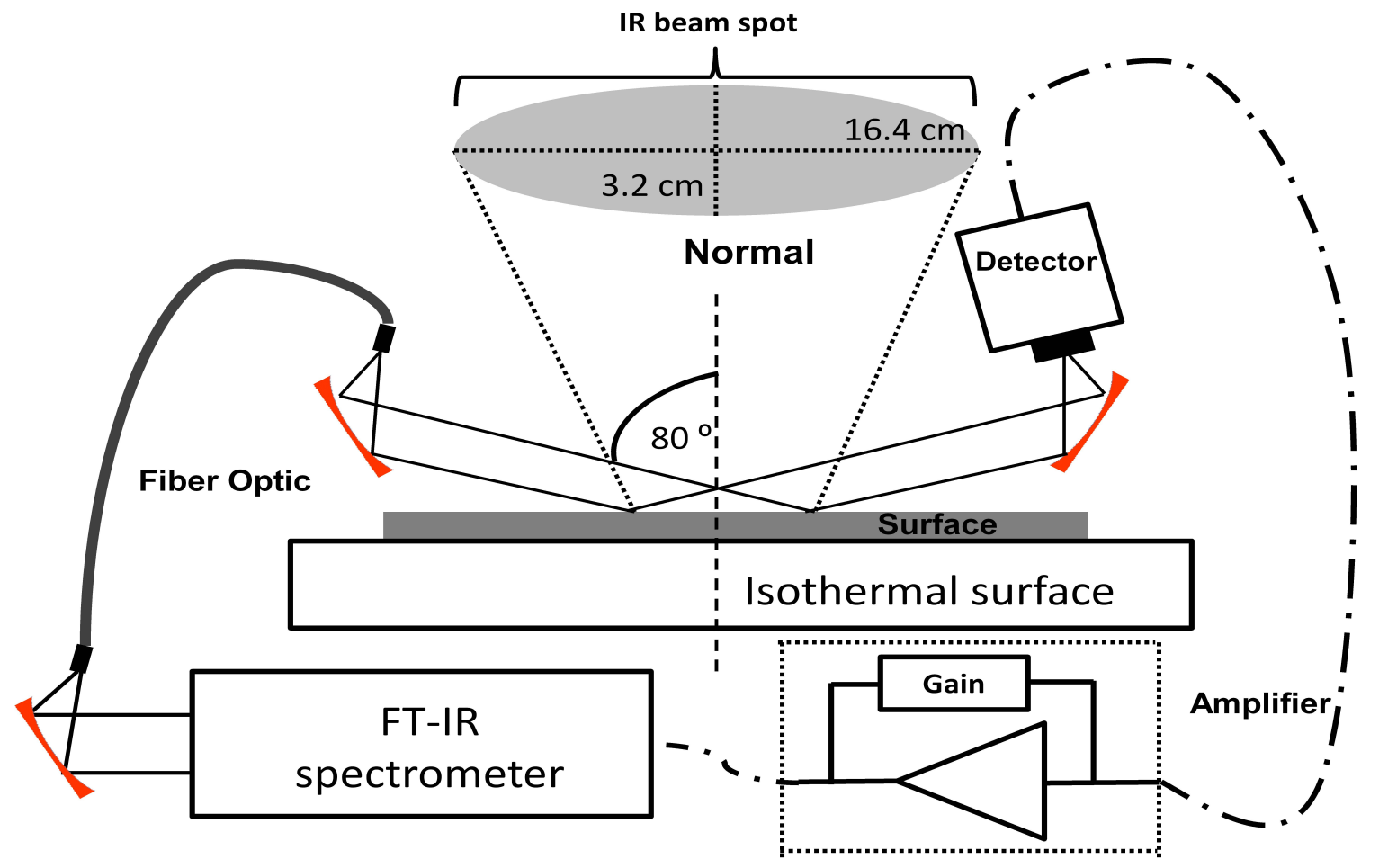

Figure 1. Grazing angle probe fiber-optic (GAP) experimental setup for the sublimation highly energetic material (HEM).

The MIR beam was reflected in an elliptical shape from the metal surface. The size of the ellipse along the major axis was $\approx 16 \mathrm{~cm}$ and along the minor axis was $\approx 3 \mathrm{~cm}$. To measure this axis, the intensity of infrared in different position on gold surface was measure using a thermal camera, the beam intensity pattern on the surface was well described by a Gaussian distribution [27]. The behavior of the relative intensity $\left(I_{r}\right)$ was measured and can be fitted as Equation (1):

$$
I_{r}=\exp \left[-(0.10 \pm 0.01) x^{2}-(3.3 \pm 0.2) y^{2}\right]
$$

Rewriting Equation (1),

$$
\left(\frac{x}{3.2}\right)^{2}+\left(\frac{y}{0.6}\right)^{2}=-\ln \left(I_{r}\right)
$$

This expression describes an ellipse with the major axis measuring $3.4 \mathrm{~cm}$ and the minor axis measuring $0.6 \mathrm{~cm}$. These values for the axes represent an ellipse that contains $63.2 \%$ of the infrared 
beam [28]. For 99\% reflection of the MIR light on the surface, the ellipse had dimensions of $6.8 \mathrm{~cm}$ on the major axis and $1.2 \mathrm{~cm}$ on the minor axis Infrared microscopy in the MIR region was also used to characterize the samples. A Bruker Optics model IFS 66v/S spectrometer coupled to a Hyperion II IR microscope equipped with GAO was used. A computer-controlled motorized stage, a cryocooled MCT detector and a potassium bromide $(\mathrm{KBr})$ beam splitter allowed sampling of areas with dimensions of $100 \times 100 \mu \mathrm{m}^{2}$. TGA was done using a model Q-500 (TA Instruments, New Castle, DE, USA) for all bulk measurements. A constant ultrahigh purity nitrogen flow of $40 \mathrm{~mL} / \mathrm{min}$ was used to run the samples. Standard platinum sample holders were used. Aluminum pans on top of the platinum holders were used to contain the samples to a specific area. The TGA was temperature calibrated using the nickel Curie point $\left(356^{\circ} \mathrm{C}\right)$ apparent weight loss according to manufacturer-optimized procedures.

\subsection{Sublimation Study by Thermal Analysis}

TGA is a rapid and convenient method for obtaining vapor pressure curves and the enthalpies of sublimation and vaporization of volatile materials. However, TGA cannot be used for measuring the sublimation of thin layers because the limit of mass determination of a TGA apparatus is higher than the mass of a thin layer. For example, for a surface of $1 \mathrm{~cm}^{2}$ that contains $0.1 \mu \mathrm{g} / \mathrm{cm}^{2}$ of material, the total mass is $100 \mathrm{ng}(0.1 \mu \mathrm{g})$, which is too low to be measured by the microbalance in a conventional TGA instrument [29]. TGA methods for measuring vapor pressure and sublimation enthalpies are based on the principle that sublimation, as well as evaporation, is a zero-order process. Thus, the mass loss under isothermal conditions must be constant $[21,30]$. The mathematical expression that correlates the vapor pressure originates from Langmuir's work of 1913 [31]:

$$
\left(\frac{1}{\text { area }}\right)\left(\frac{d m}{d t}\right)=p \alpha_{v}\left(\frac{M}{2 \pi R_{g} T}\right)^{0.5}
$$

where $(1 /$ area $)(d m / d t)$ is the rate of mass loss per unit area, $p$ is the vapor pressure, $M$ is the molecular mass of the evaporating compound, $R_{g}$ is the gas constant, $T$ is the absolute temperature $(\mathrm{K})$, and $\alpha_{v}$ is the vaporization coefficient. In a vacuum, $\alpha_{v}$ is assumed to be 1 , but in a flowing gas, such as that used in TGA experiments, $\alpha_{v}$ can have different values. Rearranging the Langmuir equation results in

$$
p=k_{t} v_{s}
$$

where $\mathrm{k}_{t}=(1 /$ area $)\left(\left(2 \pi \mathrm{R}_{g}\right)^{0.5} / \alpha_{v}\right)$ and $v_{s}=(\mathrm{dm} / \mathrm{dt})(\mathrm{T} / \mathrm{M})^{0.5}$. If a compound is thermally stable and its vapor pressures at different temperatures are known, it is possible to correlate the vapor pressure to the mass loss rates obtained by TGA from which $k_{t}$ is obtained [32]. This can be used to determine the vapor pressure of other substances. The study of the sublimation kinetics of HEMs by TGA involves determining the rate of mass loss at several isothermal points over the temperature range of interest. In the present study, the mass of the samples was monitored under isothermal conditions for a minimum of $30 \mathrm{~min}$. The temperature range was different for each explosive at data intervals of $5{ }^{\circ} \mathrm{C}, 1{ }^{\circ} \mathrm{C}$, and $0.5^{\circ} \mathrm{C}$. For TATP, the temperature range was 20 to $65^{\circ} \mathrm{C}$; for 2,4 -DNT, the range was $25-70{ }^{\circ} \mathrm{C}$; for $\mathrm{TNT}$, the range was 30 to $90^{\circ} \mathrm{C}$; and for $\mathrm{RDX}$, the range was 50 to $125^{\circ} \mathrm{C}$. To determine the vapor pressure, the rate of mass loss for benzoic acid was measured every $2{ }^{\circ} \mathrm{C}$ from 22 to $90{ }^{\circ} \mathrm{C}$. The value of $v_{s}$ was calculated, and the value of $\mathrm{k}_{t}$ was obtained by fitting the vapor pressures in the literature $[33,34]$.

\subsection{Sublimation Study by GAP}

The sublimation of thin layers and trace amounts of HEMs was studied by FTIR-GAP. Samples were prepared by depositing the HEMs from liquid solutions, generating homogeneous distributions on the surfaces of the SS substrates after drying at room temperature. The morphologies of the residues of the HEMs on the SS surfaces were terraces for TATP, droplets for 2,4-DNT and TNT, and layers for RDX, as determined using optical microscopy at 100× magnification (see Supplementary Material). 
The initial concentrations varied depending on differences in the solubilities and vapor pressures of the materials. Aliquots of $20 \mu \mathrm{L}$ of HEMs standard solutions were deposited on one side of the SS substrates, and then evenly distributed using a sample smearing method [26]. Isopropanol was used as the solvent for RDX, TNT, and 2,4-DNT, and dichloromethane was used for TATP because of its high vapor pressure, which means that a more volatile solvent is required. For the determination of thermodynamic properties, MIR spectra were recorded as a function of time at different temperatures. For TATP, initial surface loadings $\left(\mathrm{Cs}_{\circ}\right)$ of 25,50 , and $80 \mu \mathrm{g} / \mathrm{cm}^{2}$ were used between 14 and $36{ }^{\circ} \mathrm{C}$. The $\mathrm{Cs}_{\circ}$ values for 2,4-DNT were 2.8, 5.7, and $11.4 \mu \mathrm{g} / \mathrm{cm}^{2}$ and for TNT were 3.8, 7.6, and $11.4 \mu \mathrm{g} / \mathrm{cm}^{2}$. The temperatures studied were $23-60{ }^{\circ} \mathrm{C}$ for 2,4 -DNT and $22,30,40,50,55$ and $70{ }^{\circ} \mathrm{C}$ for TNT. For RDX, only $C s_{\circ}$ values of 0.7 and $1.4 \mu \mathrm{g} / \mathrm{cm}^{2}$ were studied at $22,44,65,75$, and $80{ }^{\circ} \mathrm{C}$. For each temperature, the measurements were carried out in triplicate. The sublimation rate of RDX at room temperature $\left(22{ }^{\circ} \mathrm{C}\right)$ was monitored over 258 days to consider the signal decay.

\subsection{Desorption Energy}

Due to the low vapor pressure of RDX, its desorption energy was also studied by TDS. A temperature-programmed method (TPM) was used. A first-order desorption rate $\left(r_{\text {des }}\right)$ was obtained for the RDX on SS substrates. For a first-order rate, the value of surface concentration or surface loading (Cs) is proportional to the $r_{d e s}$ and corresponds to the simplest case of single molecules desorbing directly and independently from sites on the surface. The $r_{d e s}$ is related to $C s$ and $T$ via Equation (5). The units for $k$ and $k^{\circ}$ are $s^{-1}$ (frequency units), and these are related to each other, $\Delta_{d e s} U, k^{\circ}$, and the Boltzmann constant $\left(k_{B}\right)$ through an Arrhenius type relationship (Equation (5)). This frequency is called the attempt frequency, and it is of the order of crystal lattice atomic frequencies $\left(\cong 10^{13} \mathrm{~s}^{-1}\right)$ [35].

$$
r_{d e s}=-\frac{d C s}{d t}=k C s^{n}=k^{\circ} C s^{n} \exp \left(-\frac{\Delta_{d e s} U}{k_{B} T}\right)
$$

where $n$ is the surface desorption rate order. It is assumed that all adsorbed molecules occupy identical sites on the surface and that they do not interact with each other. In TPM, there are two possible regimes of data acquisition: flash desorption and adiabatic (slow) desorption. Slow desorption is commonly used for TPM by TDS. Here, the vapor pressure is proportional to $r_{d e s}$, and the heating rate $\left(\beta_{h}=d T / d t\right)$ used must be linear. Then, Equation (5) is transformed into Equation (6):

$$
p(T) \propto-\frac{d C s}{d t} \frac{1}{\beta_{h}}=-\frac{d C s}{d T}=\frac{k^{\circ} C s^{n}}{\beta_{h}} \exp \left(-\frac{\Delta_{d e s} U}{k_{B} T}\right)
$$

The desorption rate divided by the heating rate $\left(r_{\text {des }} / \beta_{h}\right)$ increases at the beginning of the temperature ramp on sample heating, but decreases at the end of the temperature program because the adsorbate coverage is spent. The vapor pressure depends on $T$ and has a maximum value at $T_{\max }$ that is related to $\Delta_{d e s} U$, the desorption rate order $(n)$, and $k^{\circ}$. In the case of first-order kinetics [36], Equation (6) is derived and set equal to zero to find the maximum:

$$
\ln \left(\frac{\beta_{h}}{T_{\max }^{2}}\right)=-\frac{\Delta_{d e s} U}{k_{B}} \frac{1}{T_{\max }}+\ln \left(\frac{k^{\circ} k_{B}}{\Delta_{\text {des }} U}\right)
$$

To measure Cs with time and temperature, GAO measurements using polarized MIR light were used. IR reflectance spectra were measured at different $\beta_{s u b} h$ and initial surface loadings $\left(C s_{\circ}\right)$. The relationship between $C$ s, density $(\rho)$, and thickness $(d)$ is shown in Equation (8), and the relationship between $\Delta R / R_{\circ}$ (where $R$ is the reflectance, $\Delta R$ is $R_{\circ}-R$, and $R_{\circ}$ is the baseline reflectance) and $d$ is given in Equation (8) [37].

$$
d=\frac{C s}{\rho}
$$




$$
\left(\frac{\Delta R}{R_{\circ}}\right)_{S} \cong 1-R_{S} \cong-8 \pi d v \operatorname{Im}(\epsilon) \cos (\phi) \propto C s
$$

or

$$
\left(\frac{\Delta R}{R_{\circ}}\right)_{p} \cong 1-R_{p} \cong-8 \pi d v \operatorname{Im}\left(\frac{1}{\epsilon}\right) \sin (\phi) \tan (\phi) \propto C s
$$

where $R_{S}$ is the reflectance with the component of the electric field vector $E_{S}$ oriented perpendicular to the plane of incidence, $R_{p}$ is the component of the electric field vector $E_{p}$ oriented parallel to the plane of incidence, $v$ is the frequency of vibration of some mode, $\phi$ is the angle of incidence, $\operatorname{Im}(\epsilon)$ is the imaginary part of the dielectric constant of the substance deposited (or energy loss function), and $\operatorname{Im}(1 / \epsilon)$ is the imaginary part of the inverse dielectric constant of the substance deposited (or longitudinal optical energy loss function). Combing Equations (8)-(10), a relationship between $\left(\Delta R / R_{\circ}\right)_{s, p}$ and $C s$ is derived. Equations (9) and (10) can be well approximated for $d<<\lambda$, where $\lambda$ is the IR wavelength, which is in the order of $10,000 \mathrm{~nm}$ or larger. Values of $d$ between 1 to $100 \mathrm{~nm}$ are considered ideal values. Logistic sigmoid fits were obtained from plots of $\Delta R / R_{\circ}$ vs. $T$ for various modes and substances (see Equation (11)), where $A, B$, and $a_{\circ}$ are constants. Next, the derivative of $\Delta R / R_{\circ}$ with respect to $T$ was

$$
\left(\frac{\Delta R}{R_{\circ}}\right)=\left(\frac{\Delta R}{R_{\circ}}\right)_{s}+\left(\frac{\Delta R}{R_{\circ}}\right)_{p}=\frac{A}{1+\exp \left(a_{\circ}\left(T-T_{\max }\right)\right)}+B
$$

\section{Results and Discussion}

\subsection{Spectroscopic Signatures}

Figure $2 \mathrm{a}-\mathrm{d}$ shows the decay of the vibrational IR signals for the HEMs studied. IR spectra were recorded every $12 \mathrm{~s}$ using GAP spectroscopy. For TATP, the peak area $\left(A_{p}\right)$ between 1330 and $1407 \mathrm{~cm}^{-1}$ was calculated for each spectrum. Two bands located in the wavenumber range of 1330 to $1407 \mathrm{~cm}^{-1}$ were selected because they are isolated and are relatively narrow in comparison with the others. These vibrations were assigned as the out-of-plane bending of the methyl group $\delta_{a s}\left(\mathrm{CH}_{3}\right)$ by Buttigieg et al. [38] Brauer et al. [39] assigned that combination to CCC asymmetric stretching and CCO bending. For 2,4-DNT and TNT, the prominent signal located at $1343 \mathrm{~cm}^{-1}$ was used. This signal was assigned to $\mathrm{C}-\mathrm{NO}_{2}$ vibration coupled to $\mathrm{C}-\mathrm{N}$ stretching [40-42] (Figure 2b,c). This band was used for monitoring the kinetic behavior of the nitroaromatic compounds. The range used to calculate the areas was 1324 to $1372 \mathrm{~cm}^{-1}$. $A_{p}$ for a characteristic MIR region has an exponential decay. Thus, a fit to a natural logarithm function in terms of $\ln \left(A-A_{\infty}\right)$ vs. time was applied to determine the sublimation constants $(k)$ for TATP, 2,4-DNT, and TNT from the slopes (see Supplementary Material). Figure 2d shows the decay of the IR signals for RDX. The behavior of the area for the band at $1264 \mathrm{~cm}^{-1}$ and the band at $1321 \mathrm{~cm}^{-1}\left(\mathrm{~N}-\mathrm{NO}_{2}\right.$ symmetrical stretching [43-48]) vs. time are approximately linear. However, the IR intensity decay vs. time is exponential for the $1593 \mathrm{~cm}^{-1}$ band $\left(\mathrm{N}-\mathrm{NO}_{2}\right.$ asymmetrical stretching [43-45]). To determine the true behavior of RDX sublimation, a calibration curve using multivariate chemometrics methods was obtained and used for the prediction of Cs. Next, Cs vs. time was plotted, and the exponential behavior was observed. 

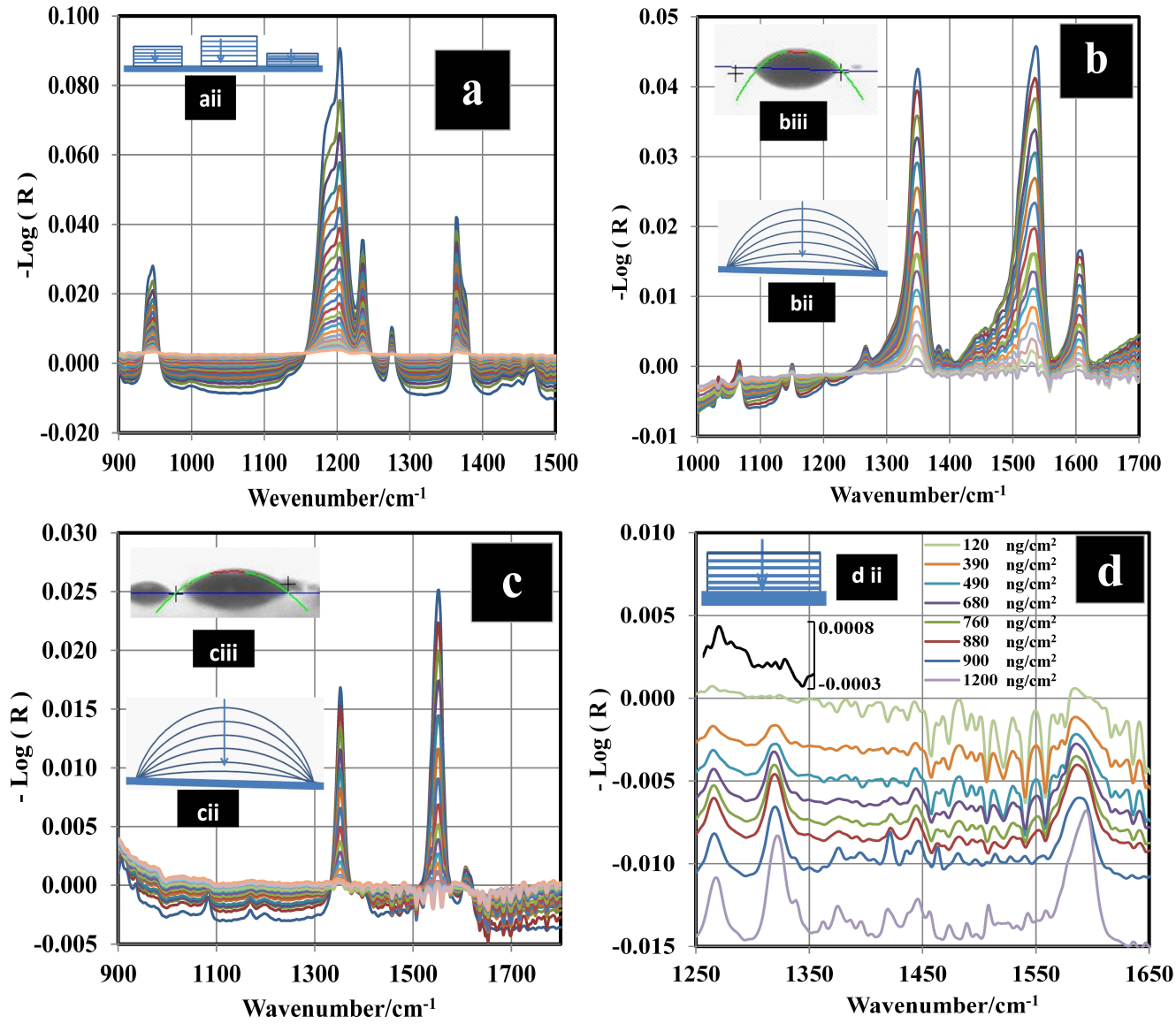

Figure 2. Mid-infrared (MIR) reflectance spectra for different HEMs undergoing sublimation on stainless steel (SS) surfaces. (a) TATP at $24{ }^{\circ} \mathrm{C}$, (b) 2,4-DNT at $35^{\circ} \mathrm{C}$, (c) TNT at $70{ }^{\circ} \mathrm{C}$, and (d) RDX at $80^{\circ} \mathrm{C}$.

\subsection{Determination of Surface Concentration and Thickness for RDX}

Calibration curves were prepared with the GAP spectral data for RDX using a PLS regression algorithm [49-53] in the Quant2 software package by Bruker Optics OPUS (version 4.2). Samples with RDX surface loadings were prepared using a smearing method [26,54-56] at room temperature. Thirty-six standard Cs from 100 to $1000 \mathrm{ng} / \mathrm{cm}^{2}$ were used for the calibration curve. The Cs standards were verified using a high-performance liquid chromatography (HPLC) technique reported by Wrable-Rose et al. [57] (see Supplementary Material). The regions used for the analyses were $1000-1260 \mathrm{~cm}^{-1}, 1314-1380 \mathrm{~cm}^{-1}$, and $1560-1634 \mathrm{~cm}^{-1}$. Vector normalization (VN) preprocessing was applied to the spectroscopic data. VN normalizes a spectrum by first calculating the average intensity value and subsequent subtraction of this value from the spectrum. Then, the sum of the squared intensities is calculated, and the spectrum is divided by the square root of this sum. This method is used to account for differences in samples thickness [58]. Cross validations were performed, and the root-mean-square errors of cross validations (RMSECVs), root-mean-square errors of estimations (RMSEEs), and correlation coefficient squared $\left(\mathrm{R}^{2}\right)$ were used as criteria to evaluate the quality of the correlations obtained. The optimum calibration curve had an RMSEE of $6 \mathrm{ng} / \mathrm{cm}^{2}$, an RMSECV of $8 \mathrm{ng} / \mathrm{cm}^{2}$, an $\mathrm{R}^{2}$ of calibration of 0.9997 , and an $\mathrm{R}^{2}$ of validation of 0.9993 . The model was obtained from five loading vectors for the spectroscopic data, and the significance of the statistics was at the level of $p=0.0001$. The limit of detection (LOD) was calculated according to Equation (12) [59-61], where $\Delta(\alpha, \beta, g)$ is a statistical parameter that takes into account the $\alpha_{p}$ and $\beta_{p}$ probabilities of falsely stating for the $g$ free degree, and the leverage, $h_{\circ}$, quantifies the distance of the predicted sample at 
zero concentration level to the mean of the calibration set. Figure 3 shows the PLS model derived from the data and the ideal model $(y=x)$.

$$
\left.L O D=\Delta\left(\alpha_{p}, \beta_{p}, g\right)\right) R M S E E\left(1+h_{\circ}\right)^{0.5}
$$

The value obtained for the LOD with the PLS model was $22 \mathrm{ng} / \mathrm{cm}^{2}$; this value is very low but it is in the order of published in the literature for RDX from grazing angle [62]. A second model using classical least squares (CLS) regression (or linear regression) was used for comparison. The results are shown in Figure 3 where the peak areas at $1321 \mathrm{~cm}^{-1}$ were used for the regression. Peak areas are shown on a second $y$-axis in Figure 3. The correlation coefficient obtained was $\mathrm{R}^{2}=0.9896$, and the $L O D$ value was $103 \mathrm{ng} / \mathrm{cm}^{2}$. This was calculated as three times the standard deviation of the intercept between slopes $[63,64]$. The LOD for this model is larger than the one obtained using PLS because the signal at $1321 \mathrm{~cm}^{-1}$ disappears almost entirely for a surface loading of $120 \mathrm{ng} / \mathrm{cm}^{2}$ (Figure $2 \mathrm{~d}$ ). This does not happen for the signal at $1594 \mathrm{~cm}^{-1}$, but a good linear CLS model could not be obtained for this signal. As shown in Figure 4, the predicted Cs from the PLS model vs. time exhibits exponential behavior. The value of $\mathrm{k}$ was determined for various temperatures (see Supplementary Material). When the surface concentration is low, several bands disappear. However, the vibrational signals in the range of 1400 to $1650 \mathrm{~cm}^{-1}$ are highly persistent. A red shift is observed when the concentration diminishes or approaches monolayer coverage. In particular, red shifts of $2 \mathrm{~cm}^{-1}$ for the band at $1321 \mathrm{~cm}^{-1}$ and $3 \mathrm{~cm}^{-1}$ for the band at $1268 \mathrm{~cm}^{-1}$ are observed (see Figure $2 \mathrm{~d}$ ). A larger red shift for the band at $1594 \mathrm{~cm}^{-1}$ is observed $\left(6 \mathrm{~cm}^{-1}\right)$, but it is not possible to determine it exactly because vibrational signals for water are present in this range.

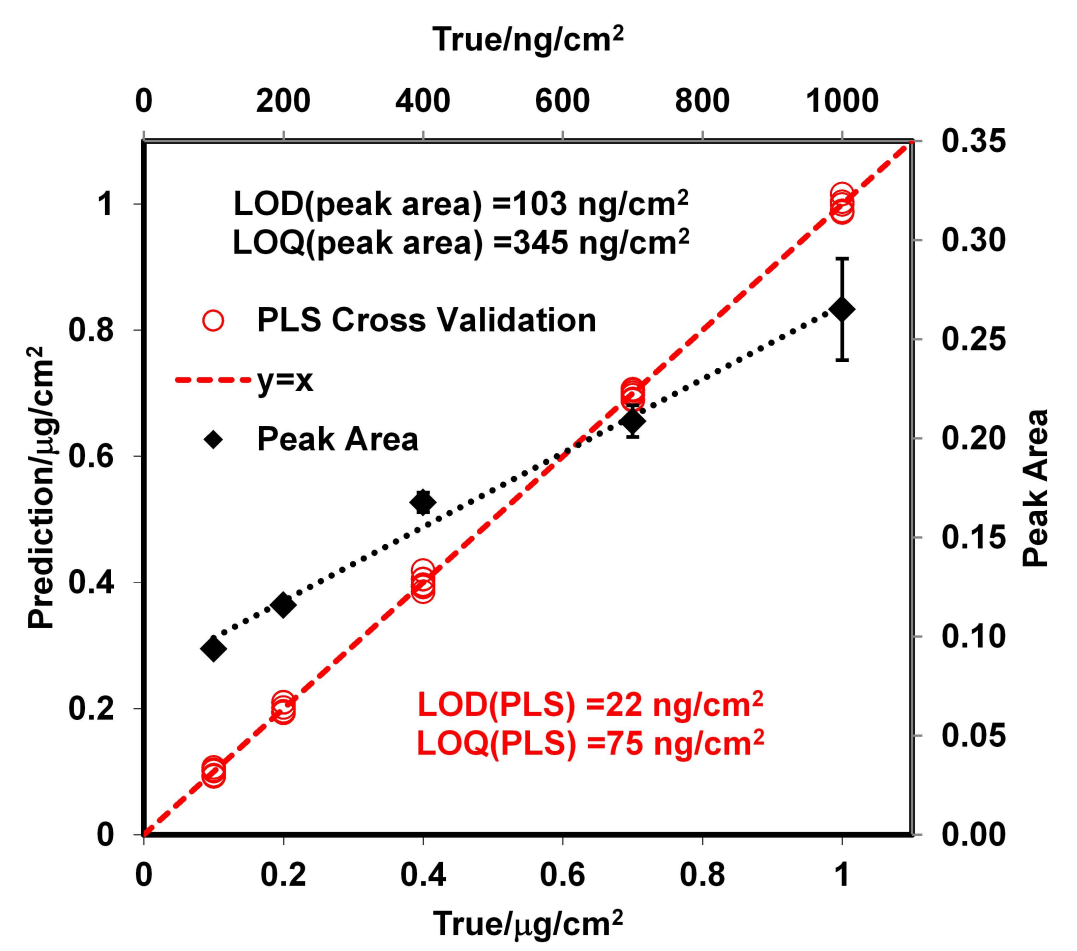

Figure 3. Calibration curves for RDX on SS by classical least squares (CLS) and PLS models.

At low surface concentrations, where RDX is near to monolayer coverage, the effect of the interaction of RDX with the surface is most noticeable. RDX can interact with the metal surface through the $\mathrm{NO}_{2}$ group. This weakens the $\mathrm{NO}$ bond, thus explaining the red shift as well as the smaller red shift exhibited by the $\mathrm{N}-\mathrm{NO}_{2}$ symmetric stretching band. The $\mathrm{NO}_{2}$ group interacts with the surface, reducing its mobility. This adds another component to the reduced mass of the oscillator, causing 
a decrease in frequency. Only one peak at $1594 \mathrm{~cm}^{-1}$ is observed for this layer, but two bands are typically exhibited by bulk samples at room temperature ( $\alpha$ phase polymorph of RDX). The peaks in the spectrum of bulk RDX are observed at 1574 and $1596 \mathrm{~cm}^{-1}$ (see Supplementary Material). It has been suggested that the $\beta$ phase crystalline polymorph of RDX ( $\beta$-RDX) [43] is present in this layer (see Figure $2 \mathrm{~d}$ and Supplementary Material). $\alpha$-RDX and $\beta$-RDX are conformational polymorphs [65] that can be differentiated using vibrational spectroscopy (Raman or MIR).

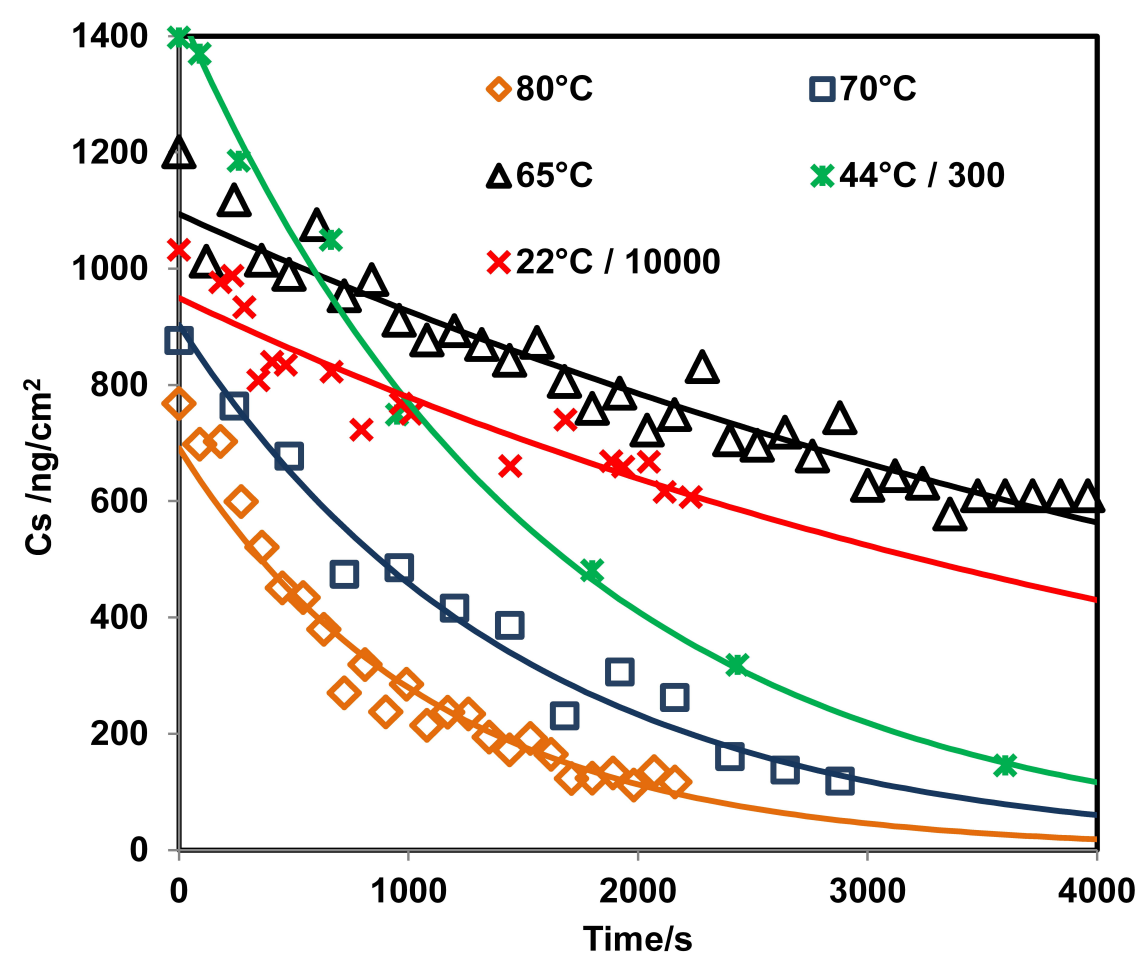

Figure 4. Prediction of Cs using the PLS model vs. time for RDX on SS at different temperatures.

\subsection{GAP vs. GAO Measurements for RDX}

A validation of GAP for RDX was carried out by comparing the results from GAP measurements with those obtained using GAO. No significant spectral differences between GAP and GAO spectra were observed for the range of 1000 to $1600 \mathrm{~cm}^{-1}$ (see Supplementary Material). However, a difference in the instrument detection capability was observed. The calculated signal-to-noise ratios (SNRs) for measurements using GAP were much larger than the corresponding values obtained by calculations using GAO measurements, particularly when the number of scans is small. These differences in SNRs decrease when the number of scans is large. The signal at $1594 \mathrm{~cm}^{-1}$ was used to calculate the values of the SNRs, and the noise was calculated from root-mean-square (RMS) values for baseline levels in the 1900 to $2100 \mathrm{~cm}^{-1}$ region. GAP measurements show a higher SNR at a low number of scans because the area averaged is larger than that for GAO and spatial averaging of a large area tends to decrease the noise levels obtained (see Supplementary Material). This suggests that GAP may be used for measuring surface kinetic processes that require small time intervals (the time for one scan at a resolution of $4 \mathrm{~cm}^{-1}$ and $10 \mathrm{KHz}$ scanning velocity is approximately $0.5 \mathrm{~s}$ ).

\subsection{Sublimation Enthalpies and Desorption Energies}

Two different methods were used to determine $\Delta_{\text {sub }} H$, i.e., TGA and GAP, and a third was used to determine the desorption energy, i.e., TPM $\left(\Delta_{\text {des }} U\right)$. Using the TGA approach, $\Delta_{\text {sub }} H$ was calculated from a linear fit of $-R_{g} \ln \left(v_{s}\right)$ and $1 / T$, where the slope corresponds to the enthalpy of sublimation and $R_{g}$ is the ideal gas constant. This approach worked well for all cases except for TATP, 
because in this case the fit was not linear (see Figure 5). For TATP, a multiple regression analysis was performed, in which $-R_{g} \ln \left(v_{S}\right)$ was related to a three-term fit: $1 / T, \ln (1 / T)$, and a constant (see Equation (13)) [66]. Next, the derivatives with respect to $1 / T$ for the simple linear models and for the multiple-terms model were obtained to calculate the $\Delta_{s u b} H$ for the bulk phase of the HEMs studied (see Equations (14) and (15)).

$$
\begin{gathered}
-R_{g} \ln (\zeta)=a \frac{1}{T}+b \ln \left(\frac{1}{T}\right)+c \\
\Delta H=-R_{g}\left(\frac{\partial \ln \left(v_{s}\right)}{\partial\left(\frac{1}{T}\right)}\right)=-R_{g}\left(\frac{\partial \ln (k)}{\partial\left(\frac{1}{T}\right)}+T\right)=\Delta_{\text {sub }} U+R_{g} T
\end{gathered}
$$

where $\zeta$ is $\mathrm{k}$ or $v_{s}$. The model described by Equation (13) was evaluated using the $p$-value of the model; the parameters $a, b$, and $c$; and the correlation coefficient $\left(R^{2}\right)$. A value of $p<0.0001$ was found for the parameter and models, indicating a high statistical significance for both TGA and GAP for TATP. The model in Equation (13) was used for TATP, but when this was applied for the other explosives, the $\mathrm{p}$ values indicated insufficient significance. This indicates a simple linear behavior of $\ln \left(v_{s}\right) \mathrm{vs}$. $1 / T$, and that the changes in heat capacity $\left(\Delta C_{p}\right)$ are near zero (or that their values are within the errors of the experiment). This result indicates that the change in the heat capacity is more significant in the temperature range studied for TATP than for the other explosives.

$$
\Delta H(T)=a+b T=\Delta H_{\text {mean }}+\Delta C_{p}\left(T_{\text {mean }}-T\right)
$$

The GAP and TGA data for TATP were evaluated using a nonrandom residual analysis for simple linear models, and a random residual for the model described with Equation (13). For the other explosives, a random residual trend for the simple linear models was observed. The advantage of the model, described by Equation (13), is that the first derivate with respect to $1 / T$ is a linear function of $T$. $\Delta H$ can be calculated for every temperature in the range evaluated from Equation (15), where $\Delta C_{p}$ is the difference between the heat capacity of TATP in the gas phase and that in the solid phase $\left(\Delta C_{p}=\right.$ $C_{p}$ (solid) $-C_{p}$ (gas) $\left.=-b\right)$, The uncertainties in $\Delta H$ in the media temperature should be lower than for every other temperature [67]. Uncertainties $(\sigma)$ in $\Delta H$ were calculated from direct contribution from the model and the indirect contribution [68], calculated from the propagation of uncertainties [69] (see Supplementary Material).

TPM was used to obtain the energy of interaction between the HEM and the surface. There are three possible hypotheses for a substance deposited on a surface. First, if the energy of interaction $\left(\Delta_{\text {int }} U\right)$ has a value comparable to $\Delta_{s u b} H$ or lower, then the value of $\Delta_{d e s} U$ can be approximated by the sum of $\Delta_{i n t} U$ and $\left(\Delta_{\text {sub }} H-R_{g} T_{\text {mean }}\right)$. Second, if $\Delta_{\text {int }} U$ is zero or very small, then $\Delta_{\text {des }} U$ is approximately $\Delta_{s u b} H-R_{g} T_{\text {mean }}$. Third, if $\Delta_{i n t} U$ is larger than $\Delta_{s u b} H$, two decays of $C s$ should be observed by TPM; first, a decay of bulk coverage by sublimation followed by a second decay of the monolayer coverage. The values for the calculated thermodynamic parameters $\Delta_{\text {sub }} H$ and $\Delta_{\text {des }} U$ $\Delta_{\text {sub }} H$ were calculate from $\Delta_{\text {des }} U+R_{g} T$ are shown in Table 1 . Three models were obtained for TATP from TGA measurements. The first model for the sublimation obtained from the rate of sublimation measurements at different temperatures used a $\Delta T$ of $5^{\circ} \mathrm{C}$ (see Figure 5; labeled as TATP_TGA_1; table included as part of the Supplementary Materials). The rates were measured at $1^{\circ} \mathrm{C}$ and $0.5^{\circ} \mathrm{C}$ (see Figure 5). Labels used were TATP_TGA_2 and TATP_TGA_3, respectively. The table containing these results can also be found in the Supplementary Materials. The TGA experiments for TATP were performed in triplicate to prove that it was not a simple linear case. The samples used came from two different syntheses, and the time difference between the two sets of experiments was six months. $\Delta_{\text {sub }} H$ at $T_{\text {mean }}=37.82{ }^{\circ} \mathrm{C}$ was $83 \pm 5 \mathrm{~kJ} / \mathrm{mol}$ for the first experiment and $87 \pm 3 \mathrm{~kJ} / \mathrm{mol}$ and $86 \pm 2 \mathrm{~kJ} / \mathrm{mol}$ at $T_{\text {mean }}=43.00{ }^{\circ} \mathrm{C}$ and $T_{\text {mean }}=37.80{ }^{\circ} \mathrm{C}$, respectively, for the second and third experiments. The value of $\Delta_{\text {sub }} H$ for TATP using GAP was $140 \pm 14 \mathrm{~kJ} / \mathrm{mol}$ at $T_{\text {mean }}=20.9{ }^{\circ} \mathrm{C}$. These values are different to that obtained by TGA, but the $\Delta_{s u b} H$ values obtained by TGA in the temperature range of 24 to $27^{\circ} \mathrm{C}$ 
(calculated by Equation (15)) are statistically identical to $\Delta_{\text {sub }} H$ obtained by GAP (see Table 2 and Supplementary Materials). This suggests that the interaction between TATP and the substrate is very weak and that sublimation is the main phenomenon involved.

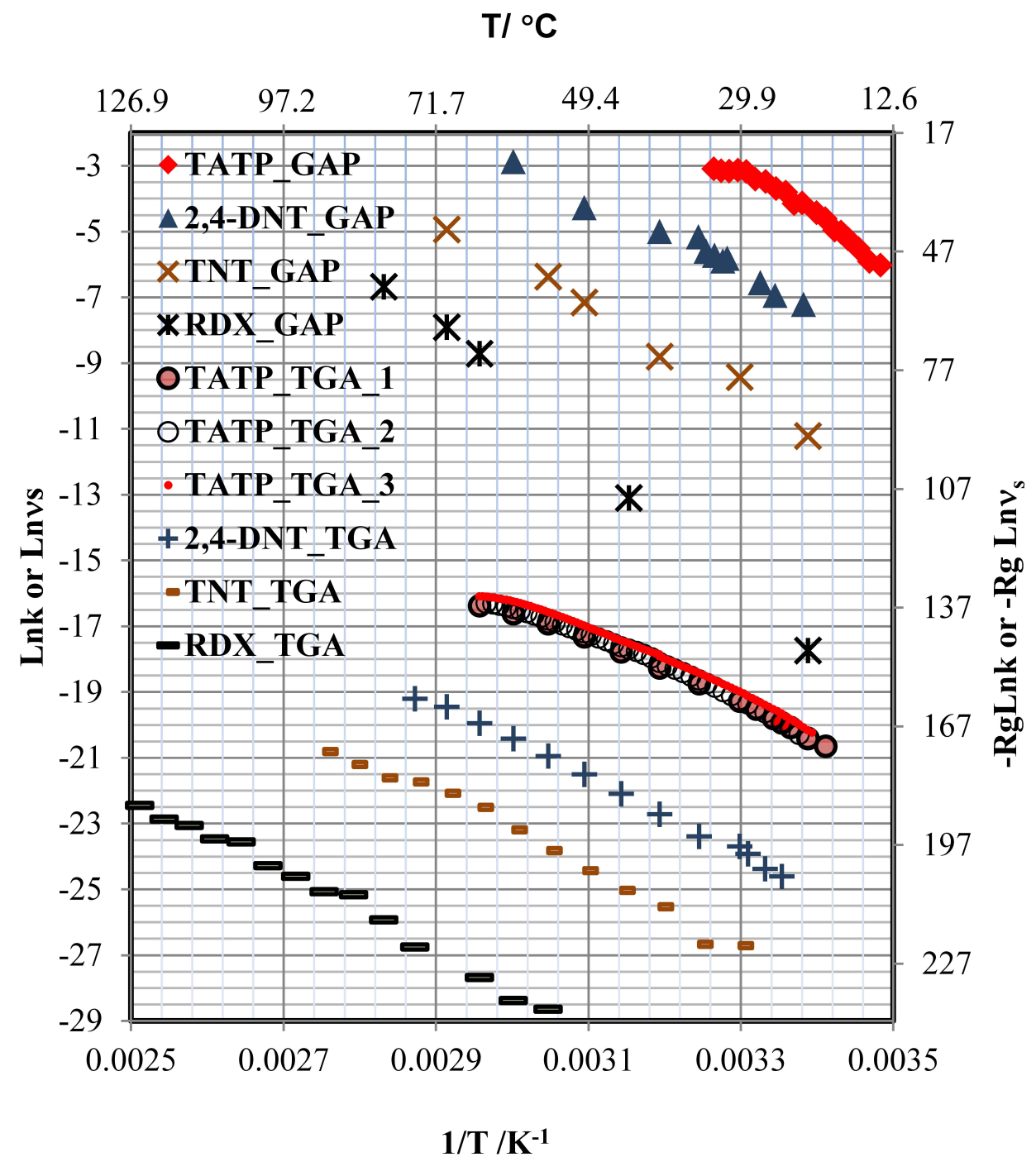

Figure 5. Arrhenius plots of GAP and TGA data used to obtain the sublimation rates for TATP, 2,4-DNT, TNT, and RDX. The units for GAP are $\mathrm{s}^{-1}$ and for TGA are $\mathrm{kg} \cdot \mathrm{s}^{-1}$.

The values obtained for $\Delta C_{p}$ by TGA and GAP are different. For TGA, the values are $1.21 \pm 0.09 \mathrm{~kJ} / \mathrm{mol} \cdot \mathrm{K}, 1.50 \pm 0.04 \mathrm{~kJ} / \mathrm{mol} \cdot \mathrm{K}$, and $1.24 \pm 0.04 \mathrm{~kJ} / \mathrm{mol} \cdot \mathrm{K}$, whereas the value for GAP is $8.6 \pm 0.9 \mathrm{~kJ} / \mathrm{mol} \cdot \mathrm{K}$. It is possible that, in GAP, the SS surface can affect the measured values due to the heat transferred from the surface and the surroundings. This hypothesis is confirmed by the fact that at room temperature, the $\Delta_{s u b} H$ values obtained by TGA and GAP are statistically identical, where heat transfer from the surface to the surroundings is almost zero. For TGA experiments, the temperature of the surroundings is equal to the sample temperature for all isothermal measurements, but for GAP, this only occurs at room temperature. This difference in $\Delta_{s u b} H$ in the absence of $\Delta_{\text {int }} U$ is only observed for explosives where $\Delta C_{p}$ is statistically different from zero. This is confirmed by fitting the model of Equation (13) to 2,4-DNT, TNT, and RDX for the $\Delta C_{p}$ values obtained by GAP and TGA (see Table 2). There are no significant differences statistically between the values obtained by GAP and TGA because the values of $\Delta C_{p}$ for these explosives is in the order of the experimental uncertainties, although for RDX in GAP the crystalline phase is $\beta$ ( $\beta$-RDX) and in TGA is $\alpha$ ( $\alpha$-RDX). 
Table 1. Enthalpy of sublimation for HEM and desorption energy for RDX on SS.

\begin{tabular}{|c|c|c|c|c|c|}
\hline $\operatorname{Exp}$ & HEM & Range of $T$ & $T_{\text {mean }} /{ }^{\circ} \mathrm{C}$ & $\Delta_{\text {sub }} H$ & $\mathbf{R}^{2}$ \\
\hline GAP & TATP & $14-33$ & 20.9 & $144 \pm 14$ & 0.997 \\
\hline TGA_1 & TATP & $20-65$ & 37.5 & $83 \pm 5$ & 0.999 \\
\hline TGA_2 & TATP & $22-64$ & 44.0 & $87 \pm 3$ & 1.000 \\
\hline TGA_3 & TATP & $21-63$ & 37.8 & $86 \pm 2$ & 1.000 \\
\hline GAP & 2,4-DNT & $23-35$ & 36.0 & $94 \pm 5$ & 0.986 \\
\hline TGA & $2,4-\mathrm{DNT}$ & $25-75$ & 46.6 & $94 \pm 2$ & 0.998 \\
\hline GAP & TNT & $40-70$ & 55.0 & $111 \pm 6$ & 0.998 \\
\hline TGA & TNT & $40-65$ & 52.5 & $95 \pm 3$ & 0.997 \\
\hline GAP & RDX & $22-80$ & 56.2 & $153 \pm 5$ & 0.998 \\
\hline TGA & RDX & 55-125 & 90.0 & $99 \pm 3$ & 0.987 \\
\hline \multirow[t]{2}{*}{ TPM } & RDX & $\Delta U / \mathrm{kJ} / \mathrm{mol}$ & $\beta_{h} /{ }^{\circ} \mathrm{C} / \mathrm{min}$ & $T_{\max } /{ }^{\circ} \mathrm{C}$ & \\
\hline & & $\Delta_{\text {int }} U=19 \pm 1$ & $\begin{array}{c}5 \\
10 \\
20\end{array}$ & $\begin{array}{l}117 \pm 2 \\
142 \pm 3 \\
200 \pm 3\end{array}$ & \\
\hline
\end{tabular}

Table 2. Enthalpies of sublimation for standards $(\mathrm{kJ} / \mathrm{mol})$ and $\Delta C_{p}(\mathrm{~kJ} / \mathrm{mol} \cdot \mathrm{K})$ for HEMs.

\begin{tabular}{ccccc}
\hline Molecule & $\boldsymbol{\Delta}_{\boldsymbol{s u b}} \boldsymbol{H}^{\circ}$ for GAP & $\boldsymbol{\Delta}_{\boldsymbol{s u b}} \boldsymbol{H}^{\circ}$ for TGA & $\boldsymbol{\Delta}_{\boldsymbol{s u b}} \boldsymbol{H}^{\circ}$ for TGA_2 & $\boldsymbol{\Delta}_{\boldsymbol{s u b}} \boldsymbol{H}^{\circ}$ for TGA_3 \\
\hline TATP & $104 \pm 15$ & $99 \pm 6$ & $107 \pm 3$ & $102 \pm 3$ \\
2,4-DNT & $103 \pm 11$ & $100 \pm 5$ & & \\
TNT & $117 \pm 31$ & $120 \pm 9$ & & \\
RDX & $165 \pm 22$ for $\beta$-RDX & $112 \pm 20$ for $\alpha$-RDX & & \\
\hline Molecule & $\boldsymbol{\Delta} \boldsymbol{C}_{\boldsymbol{p}}$ for GAP & $\boldsymbol{\Delta} \boldsymbol{C}_{\boldsymbol{p}}$ for TGA & $\boldsymbol{\Delta} \boldsymbol{C}_{\boldsymbol{p}}$ for TGA_2 & $\boldsymbol{\Delta} \boldsymbol{C}_{\boldsymbol{p}}$ for TGA_3 \\
\hline TATP & $8.6 \pm 0.9$ & $1.21 \pm 0.09$ & $1.50 \pm 0.04$ & $1.24 \pm 0.04$ \\
2,4-DNT & $1.1 \pm 0.9$ & $0.3 \pm 0.2$ & & \\
TNT & $0.3 \pm 1.0$ & $0.9 \pm 0.3$ & & \\
RDX & $0.4 \pm 0.7$ & $0.2 \pm 0.3$ & & \\
\hline
\end{tabular}

The nonlinear behavior of TATP and the high value of $\Delta C_{p}$ can be explained by the difference in the values of $\Delta_{s u b} H$ found in the literature (see Table 3). For the value of $\Delta C_{p}$ obtained from Equation (13), it was necessary for both methodologies to obtain many points of temperature and use a large range of temperatures. Data from the literature was used to obtain $\Delta C_{p}$ (see Table 3). For experiments at relatively low temperatures, $\Delta C_{p}$ is near to zero and the fit is linear. This can also be observed in Figure 5. The curvature is only prominent at high temperatures. The values of $\Delta C_{p}$ from Oxley et al. are comparable to the present results. This can be attributed to the fact that they used a small number of temperature values, which is required to obtain low uncertainties in $\Delta C_{p}$.

Table 3. Enthalpies of sublimation and $\Delta C_{p}$ values for TATP from this study and the literature.

\begin{tabular}{ccccc}
\hline & $\boldsymbol{T}_{\text {mean }}$ in ${ }^{\circ} \mathbf{C}$ & $\mathbf{N}$ of $\boldsymbol{T}$ & $\Delta \boldsymbol{C}_{\boldsymbol{p}}$ in $\mathbf{~ J J} / \mathbf{m o l} \cdot \mathbf{K}$ & $\boldsymbol{\Delta}_{\text {sub }} \boldsymbol{H}$ in $\mathbf{~ j J} / \mathbf{m o l}$ \\
\hline GAP & 20.9 & 19 & $8.6 \pm 0.9$ & $142 \pm 14$ \\
TGA_1 & 37.5 & 14 & $1.21 \pm 0.09$ & $83 \pm 5$ \\
TGA_2 & 44 & 42 & $1.50 \pm 0.04$ & $87 \pm 2$ \\
TGA_3 & 37.8 & 88 & $1.24 \pm 0.03$ & $85 \pm 2$ \\
Damour et al., 2010 [69] & 14.3 & 27 & 0 & $86.2 \pm 1$ \\
Ramirez et al., 2006 [22] & 50.0 & 7 & $0.75 \pm 0.08$ & 85.8 \\
Felix et al., 2011 [70] & 50.0 & 8 & - & 72.1 \\
Oxley et al., 2005 [71] & 40 & 6 & $0.3 \pm 0.5$ & 109 \\
Oxley et al., 2009 [72] & 32.2 & 7 & $0.6 \pm 0.7$ & 73 \\
Dunayevskiy et al., 2007 [73] & 0 & - & - & 81.3 \\
Espinosa-Fuentes et al., 2015 [74] & 46 & 32 & 1.5 & $103.8 \pm 0.2$ \\
\hline
\end{tabular}


For 2,4-DNT and TNT, the materials deposited for GAP experiments do not exist in solid crystalline forms. Rather, they adopt metastable phases in the form of droplets (see Supplementary Material). The contact angle (CA) for the droplets is $42 \pm 3^{\circ}$ for 2,4-DNT and $35 \pm 1^{\circ}$ for TNT (see Figure 2biii,ciii), indicating that 2,4-DNT has slightly less affinity for the surface than TNT. The CA changes during the sublimation process. This can be explained from the microscopic viewpoint in that molecules that interact directly with the surface and neighbors cannot be desorbed to the gas phase as easily as molecules that are far away from the surface and that are able to pass directly to the gas phase, generating a change in CA without a change in the enthalpy of sublimation. This behavior is illustrated in Figure 2bii,cii). The mechanism is similar for 2,4-DNT and TNT. This is corroborated by the existence of an isokinetic temperature found for the plot $\ln (k)$ vs. $1 / T$. The value found for the plot was $666 \mathrm{~K}$. The estimated $\Delta_{\text {sub }} H$ for the metastable forms are $91 \pm 5$ and $108 \pm 6 \mathrm{~kJ} / \mathrm{mol} \mathrm{for}$ 2,4-DNT and TNT, respectively, assuming that the interactions between the HEM and the surface are negligible. A contribution from $\Delta_{i n t} U$ for 2,4-DNT and TNT cannot be ruled out, because the end of the sublimation of the droplets leaves a film of molecules that were interacting with the surface initially. However, the value of $\Delta_{i n t} U$ for this film should be too small to be measured by TPM with TDS using GAO. The TGA method for TNT and 2,4-DNT revealed $\Delta_{\text {sub }} H$ values for the crystalline phases of $95 \pm 3$ and $94 \pm 3 \mathrm{~kJ} / \mathrm{mol}$, respectively. These values are close to the literature values (see Table 4). $\Delta_{s u b} H$ for the crystalline phase is statistically similar to $\Delta_{s u b} H$ for the metastable phase for TNT and DNT. The metastable form is described as a supercooled liquid [14]. It is possible to induce the transition from the metastable phase to crystalline phase by applying mechanical pressure. This process destabilizes the pseudo equilibrium of the metastable form and induces a change in state to the more stable crystalline form.

The size of the droplets depends on the Cs as generated in the smearing deposition method. A size distribution was obtained for different Cs values. A normal distribution was observed for TNT at all concentrations when alcohols are used as solvents in the deposition process. The distributions for 2,4-DNT are far from normal at low Cs. The distributions were obtained by capturing several images for a selected Cs and measuring the size of the droplets from the image obtained (see Supplementary Material). This analysis is important for the development of standards for solids deposited on substrates for use in explosives detection devices. This explains the higher RMSECV for 2,4-DNT than for TNT found by Primera et al. [54,55]. When RDX was deposited on the metal surface from isopropanol solutions, films were observed (see Figure 2diii and Supplementary Material). These films are made of $\beta$-RDX polymorph, different from the bulk solid. In bulk solid, $\alpha$-RDX polymorph is observed. Several previous studies have reported that the $\beta$-RDX conformer is metastable [65] relative to the $\alpha$-RDX conformer. The energy difference between the two conformations is less than $1 \mathrm{kcal} / \mathrm{mol}[44,75-77]$. The $\beta$-RDX polymorph was also formed when the RDX sample was allowed to sublimate and condense on a glass slide and upon depositing the sample from solutions [45] of various solvents (acetone, methanol, or saturated isopropanol). This is supported by the MIR spectrum and discussed above. Sublimation of solid $\alpha$-RDX and a $\beta$-RDX film were measured by TGA and GAP, respectively, and $\Delta_{s u b} H$ for the $\alpha$-RDX and $\beta$-RDX phases were obtained. The calculated value for $\alpha$-RDX is $99 \pm 3 \mathrm{~kJ} / \mathrm{mol}$ (Table 1 ). The value obtained by the GAP method for RDX is $169 \pm 5 \mathrm{~kJ} / \mathrm{mol}$. This value is $\Delta_{\text {sub }} U+\Delta_{\text {int }} U$. TPM was used to obtain $\Delta_{i n t} U$. Measurement of R for five bands $\left(1576 \mathrm{~cm}^{-1}, 1534 \mathrm{~cm}^{-1}, 1316 \mathrm{~cm}^{-1}, 1268 \mathrm{~cm}^{-1}\right.$, and $\left.909 \mathrm{~cm}^{-1}\right)$ in the spectrum of RDX at three different $\beta_{h}$ values were used to obtain $\mathrm{T}_{\text {max }}$ from the first derivate of a logistic fit (Equation (11) and red square inset in Figure 6). Next, $-R_{g} \ln \left(\beta_{h} / T_{\max }^{2}\right)$ vs. $1 / T_{\max }$ was plotted to determine the value of $\Delta_{\text {int }} U$ from the slope of the fit (Equation (7)). $\Delta_{i n t} U$ was found to be $19 \pm 1 \mathrm{~kJ} / \mathrm{mol}$, and $\Delta_{\text {sub }} U$ for $\beta$-RDX now becomes $150 \pm 5 \mathrm{~kJ} / \mathrm{mol}$ and $\Delta_{\text {sub }} H$ becomes $153 \pm 5 \mathrm{~kJ} / \mathrm{mol}$. This value is larger than the corresponding value for $\alpha$-RDX. 
Table 4. Enthalpies of sublimation for DNT, TNT, and RDX in this study and the in literature.

\begin{tabular}{|c|c|c|c|}
\hline HEM & Autor & $T_{\text {mean }} /{ }^{\circ} \mathrm{C}$ & $\Delta_{\text {sub }} H$ \\
\hline DNT & This work from GAP & 36 & $94 \pm 5$ \\
\hline DNT & This work from TGA & 46.6 & $94 \pm 2$ \\
\hline DNT & Lenchitz 1970 [78] & 64 & $98.3 \pm 2.5$ \\
\hline DNT & Lenchitz 1970 [78] & 25 & $99.6 \pm 2.5$ \\
\hline DNT & Felix et al., 2011 [70] & 52.4 & 96.2 \\
\hline DNT & Pella 1976 [79] & 37 & $95.80 \pm 1.25$ \\
\hline DNT & Lenchitz 1971 [80] & - & $99.6 \pm 1.3$ \\
\hline TNT & This work from GAP & 55 & $111 \pm 6$ \\
\hline TNT & This work from TGA & 52.5 & $95 \pm 3$ \\
\hline TNT & Edwards 1950 [81] & - & 118.4 \\
\hline TNT & Dionne et al., 1986 [82] & 25 & 113 \\
\hline TNT & Gershanik et al., 2010 [83] & 40 & $97 \pm 7$ \\
\hline TNT & Oxley et al., 2005 [71] & 36 & 137 \\
\hline TNT & Eiceman et al., 1997 [84] & 114.5 & 87 \\
\hline TNT & Leggett 1977 [85] & 26 & $141.1 \pm 0.2$ \\
\hline TNT & Hikal et al., 2014 [86] & 67.5 & $95.9 \pm 1$ \\
\hline TNT & Hikal et al., 2011 [87] & - & 100.2 \\
\hline TNT & Mu et al., 2003 [88] & 32.5 & 131 \\
\hline TNT & Chickos et al., 2002 [89] & 35 & 112.4 \\
\hline TNT & Cundall et al., 1978 [90] & 25 & $113.2 \pm 1.5$ \\
\hline TNT & Felix et al., 2011 [70] & 54.8 & 106.8 \\
\hline TNT & Pella 1977 [91] & - & $99.2 \pm 2.0$ \\
\hline TNT & Lenchitz 1971 [80] & 25 & $104.6 \pm 1.7$ \\
\hline TNT & Lenchitz 1970 [78] & 65 & $103.3 \pm 2.5$ \\
\hline TNT & Jones 1960 [92] & - & $118.4 \pm 4.2$ \\
\hline TNT & Hikal 2019 [93] & 55 & $105.9 \pm 1.4$ \\
\hline TNT & Hikal 2019 [93] & 55 & $102.1 \pm 2.7$ \\
\hline TNT & Hikal 2019 [93] & 55 & $105.8 \pm 1.6$ \\
\hline TNT & Lee 2019 [94] & 18.5 & $104.4 \pm 2.4$ \\
\hline RDX & This work from GAP & 56.2 & $150 \pm 5$ \\
\hline RDX & This work from TGA & 90 & $99 \pm 3$ \\
\hline RDX & Rosen et al., 1969 [95] & - & 130.2 \\
\hline RDX & Gershanik et al., 2012 [96] & 65 & $115-134$ \\
\hline RDX & Eiceman et al., 1997 [84] & 130 & 115 \\
\hline RDX & Hikal et al., 2011 [87] & - & 128 \\
\hline RDX & Hikal et al., 2014 [86] & 120 & $130 \pm 2$ \\
\hline RDX & Cundall et al., 1978 [90] & 25 & 134.3 \\
\hline RDX & Felix et al., 2011 [70] & 92 & 99.5 \\
\hline RDX & Chickos et al., 2002 [89] & - & $112.5 \pm 0.8$ \\
\hline RDX & Rosen et al., 1969 [95] & 77 & 130.1 \\
\hline
\end{tabular}




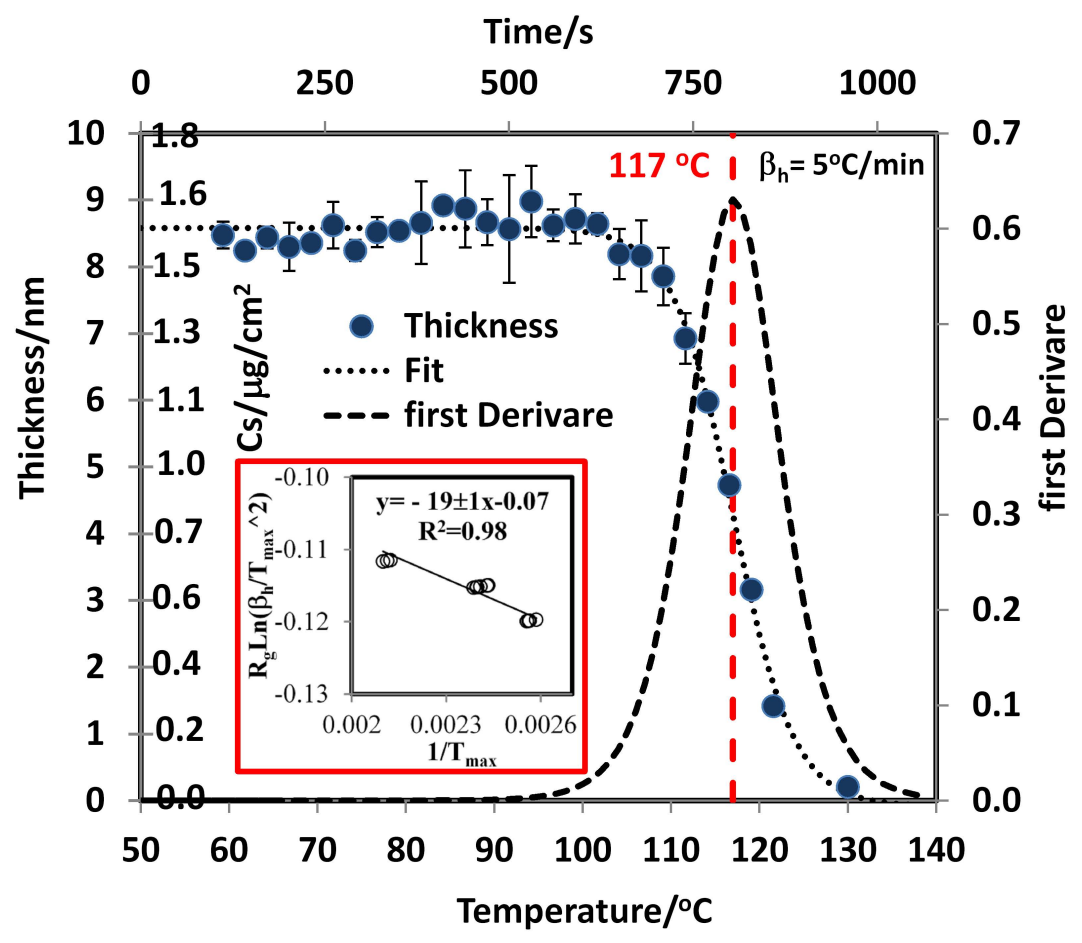

Figure 6. Plot of thickness vs. $\mathrm{T}\left({ }^{\circ} \mathrm{C}\right)$ from TPM-TDS and $\mathrm{d}(\Delta \mathrm{R} / \mathrm{R}) / \mathrm{dT}$ vs. $\mathrm{T}$.

\section{Conclusions}

Sublimation enthalpies were measured using GAP for materials that do not interact strongly with the surface and where $\Delta C_{p}$ in the temperature range of the study is zero or negligible. This is not the case for TATP because of a high value of $\Delta C_{p}$ was observed. The unexpected, temperature-dependent value for $\Delta C_{p}$ for TATP may be related to its high sensitivity to heat, friction, and shock. Using GAP, it was possible to differentiate between different phases and conformations of the materials. Using MIR techniques, the residence time of materials on surfaces was monitored, and the rates of sublimation of the materials from the surfaces were measured. The superiority of GAP over GAO found in this work is based on the detection sensitivity due to the high coverage area used in GAP. Using GAP, it is possible to detect highly energetic materials on metallic surfaces at the macro scale in $0.5 \mathrm{~s}$ ( $1 \mathrm{scan})$. Different types of mechanisms for sublimation on surfaces were found for the HEMs studied. For TATP, the sublimation takes place from small crystals to groups of islets. For 2,4-DNT and TNT, sublimation occurs from droplets that are part of a metastable phase. RDX is sublimated from a seemingly uniform coverage layer formed on the surface. The type of crystal phase that the HEMs assume on the substrate depends on surface-adsorbate adhesion forces vs. adsorbate-adsorbate intermolecular forces. Interactions between the HEMs and the surface can influence the rate of sublimation from the surface. The presence of this substrate-adsorbate interaction is demonstrated by the shift in the vibrational signals of RDX upon interaction with the SS substrate. For the case in which the interaction forces between the explosive and the surface are weak, the desorption energy should be minor compared to the sublimation enthalpy measured by TPM.

Supplementary Materials: The following are available online, Figure S1: $10 \times$ magnification micro image of morphology of residues of TATP on a SS substrate surface, Figure S2: 50× magnification micro image morphology TATP residues on a SS substrate surface, Figure S3: 10× magnification micro image of morphology of DNT residues on a SS substrate surface, Figure S4: 100× magnification micro image of morphology of DNT residues on a SS substrate surface, Figure S5: 10× magnification micro image of morphology of TNT residues on a SS substrate surface, Figure S6: 50× magnification micro image of morphology of TNT residues on a SS substrate surface, Figure S7: 10× magnification micro image of morphology of RDX residues on a SS substrate surface, Table SI: Sublimation constants for explosive from GAP measurements, Tables SII and SIII: Sublimation rate constants 
calculated from TGA measurements, Figure S8: Verification of the surface concentration of RDX by HPLC; Calibration curve for RDX by HPLC, Table SIV: Kinetics parameters and thermodynamic functions calculated from GAP, TGA, and TPM, Figure S9: (a) Plot of absorbance vs. wavenumber for RDX in KBr from macro-FTIR; (b) plot of DeltaR/R vs. wavenumber of layers of RDX from GAP at $80^{\circ} \mathrm{C}$; (c) plot of DeltaR/R vs. wavenumber of layers of RDX from GAP to $25^{\circ} \mathrm{C}$; (d) plot of DeltaR/R vs. wavenumber of layer of RDX from GAO to $25^{\circ} \mathrm{C}$; (e) Plot of DeltaR/R vs. wavenumber of SS substrate by GAO, Table SV: Signal to noise for GAP and GAO, Table SVI: Comparison of calculated Enthalpy of sublimation with literature values for TATP, Equations: Calculation of enthalpy and its uncertainties in the media temperature Figure S10: The plot of droplet size vs. surface concentration for TNT. The figure shows the standard deviation, (black line), first and third quartile (orange), and quadratic fit (dotted line), Figure S11: The plot of droplet size vs. surface concentration for 2,4-DNT. The figure shows the standard deviation, (black), first and third quartile (orange) and quadratic fit (dotted line), Figure S12: Arrhenius plots of TGA data used to obtain the sublimation rates for Benzoic acid.

Author Contributions: Conceptualization, L.C.P.-L., M.L.R.-C., and R.I.-C.; methodology, L.C.P.-L., M.L.R.-C., and R.I.-C.; validation, L.C.P.-L., N.J.G.-F., and S.P.H.-R.; formal analysis, N.J.G.-F., J.L.R.-C., and L.C.P.-L.; investigation, L.C.P.-L., M.L.R.-C., N.J.G.-F., J.L.R.-C., and R.I.-C.; resources, S.P.H.-R.; writing-original draft preparation, L.C.P.-L., M.L.R.-C., N.J.G.-F., J.L.R.-C., R.I.-C., and S.P.H.-R.; writing-review and editing, L.C.P.-L. and S.P.H.-R.; visualization, L.C.P.-L., N.J.G.-F., and J.L.R.-C.; project administration, L.C.P.-L. and S.P.H.-R.; funding acquisition, S.P.H.-R.

Funding: This material is based on work supported by the U.S. Department of Homeland Security, Science, and Technology Directorate, Office of University Programs, under Grant Award 2013-ST-061-ED0001. The views and conclusions contained in this document are those of the authors and should not be interpreted as necessarily representing the official policies, either expressed or implied, of the U.S. Department of Homeland Security. Parts of the work presented in this contribution were supported by the U.S. Department of Defense, University Research Initiative Multidisciplinary University Research Initiative (URI)-MURI Program, under grant number DAAD19-02-1-0257.

Acknowledgments: The authors also acknowledge contributions from Aaron LaPointe from Night Vision and Electronic Sensors Directorate, Fort Belvoir, VA, Department of Defense; Jennifer Becker MURI Program Manager, Army Research Office, DoD; and Stephen J. Lee Chief Scientist, Science and Technology, Office of the Director, Army Research Office/Army Research Laboratory, DoD.

Conflicts of Interest: The authors declare no conflict of interest.

\section{Abbreviations}

The following abbreviations are used in this manuscript.

GAP grazing angle probe fiber-optic

GAO grazing-angle objective

HEM highly energetic material

TGA thermogravimetric analysis

TDS thermal desorption spectroscopy

TPM temperature-programmed method

TATP triacetone triperoxide

DNT 2,4-dinitrotoluene

TNT 2,4,6-trinitrotoluene

SS stainless steel

$\Delta_{\text {des }} U$ desorption energy

$\Delta_{\text {sub }} H$ enthalpy of sublimation

$\Delta C_{p} \quad$ difference between the heat capacity

SNRs signal-to-noise ratios

MCT mercury cadmium telluride

CA contact angle

CLS classical least squares

LOD limit of detection

PLS Partial least squares regression

VN Vector normalization

HPLC high-performance liquid chromatography 


\section{References}

1. Mamo, S.K.; Gonzalez-Rodriguez, J. Development of a Molecularly Imprinted Polymer-Based Sensor for the Electrochemical Determination of Triacetone Triperoxide (TATP). Sensors 2014, 14, 23269-23282. [CrossRef] [PubMed]

2. Walter, M.A.; Panne, U.; Weller, M.G. A Novel Immunoreagent for the Specific and Sensitive Detection of the Explosive Triacetone Triperoxide (TATP). Biosensors 2011, 1, 93-106. [CrossRef] [PubMed]

3. Santos, J.P.; Fernández, M.J.; Fontecha, J.L.; Matatagui, D.; Sayago, I.; Horrillo, M.C.; Gracia, I. Nanocrystalline Tin Oxide Nanofibers Deposited by a Novel Focused Electrospinning Method. Application to the Detection of TATP Precursors. Sensors 2014, 14, 24231-24243. [CrossRef] [PubMed]

4. Lü, X.; Hao, P.; Xie, G.; Duan, J.; Gao, L.; Liu, B. A Sensor Array Realized by a Single Flexible TiO2/POMs Film to Contactless Detection of Triacetone Triperoxide. Sensors 2019, 19, 915. [CrossRef] [PubMed]

5. Sun, Q.; Wu, Z.; Duan, H.; Jia, D. Detection of Triacetone Triperoxide (TATP) Precursors with an Array of Sensors Based on MoS2/RGO Composites. Sensors 2019, 19, 1281. [CrossRef] [PubMed]

6. Nguyen, T.T.; Phan, D.N.; Nguyen, D.C.; Do, V.T.; Bach, L.G. The Chemical Compatibility and Adhesion of Energetic Materials with Several Polymers and Binders: An Experimental Study. Polymers 2018, 10, 1396. [CrossRef] [PubMed]

7. Trofimov, V.A.; Varentsova, S.A. A Possible Way for the Detection and Identification of Dangerous Substances in Ternary Mixtures Using THz Pulsed Spectroscopy. Sensors 2019, 19, 2365. [CrossRef] [PubMed]

8. Manley, P.V.; Sagan, V.; Fritschi, F.B.; Burken, J.G. Remote Sensing of Explosives-Induced Stress in Plants: Hyperspectral Imaging Analysis for Remote Detection of Unexploded Threats. Remote Sens. 2019, 11, 1827. [CrossRef]

9. Herrera-Chacon, A.; Campos, I.; Bottone, L.; Valle, M.d. Molecularly Imprinted Polymers for TNT Analogues. Development of Electrochemical TNT Biosensors. Proceedings 2017, 1, 731. [CrossRef]

10. Charles, P.T.; Wadhwa, V.; Kouyate, A.; Mesa-Donado, K.J.; Adams, A.A.; Deschamps, J.R.; Kusterbeck, A.W. A High Aspect Ratio Bifurcated 128-Microchannel Microfluidic Device for Environmental Monitoring of Explosives. Sensors 2018, 18, 1568. [CrossRef]

11. Marchisio, A.; Tulliani, J.M. Semiconducting Metal Oxides Nanocomposites for Enhanced Detection of Explosive Vapors. Ceramics 2018, 1, 98-119. [CrossRef]

12. Zarejousheghani, M.; Lorenz, W.; Vanninen, P.; Alizadeh, T.; Cämmerer, M.; Borsdorf, H. Molecularly Imprinted Polymer Materials as Selective Recognition Sorbents for Explosives: A Review. Polymers 2019, 11, 888. [CrossRef] [PubMed]

13. Attard, G.; Barnes, C. Surface; Oxford Science Publications: New York, NY, USA, 1998.

14. Galleano, M.; Boveris, A.; Puntarulo, S. Understanding the Clausius-Clapeyron Equation by Employing an Easily Adaptable Pressure Cooker. J. Chem. Educ. 2008, 85, 276. [CrossRef]

15. Sladkov, I.B.; Nedoshivina, M.S. On the accuracy of calculation by the Clapeyron-Clausius equation. Russ. J. Appl. Chem. 2001, 74, 390-393. [CrossRef]

16. Velasco, S.; Román, F.L.; White, J.A. On the Clausius-Clapeyron vapor pressure equation. J. Chem. Educ. 2009, 86, 106-111. [CrossRef]

17. Yarwood, J.L.; Le Croissette, D.H. Vapour pressure measurements of bromine. Vacuum 1951, 1, 37-38. [CrossRef]

18. Pikal, M.; Lukes, A. Knudsen Vapor Pressure Measurements on Pure Materials and Solutions Dispersed in Porous Media: Molded Nitroglycerin Tablets. J. Pharm. Sci. 1976, 65, 1269-1277. [CrossRef]

19. Elder, J.P. Sublimation measurements of pharmaceutical compounds by isothermal thermogravivletry. J. Therm. Anal. 1997, 49, 897-905. [CrossRef]

20. Jones, D.; Lightfoot, P.; Fouchard, R.; Kwok, Q. Thermal properties of DMNB, a detection agent for explosives. Thermochim. Acta 2002, 388, 159-173. [CrossRef]

21. Chatterjee, K.; Dollimore, D.; Alexander, K.S. Calculation of vapor pressure curves for hydroxy benzoic acid derivatives using thermogravimetry. Thermochim. Acta 2002, 392-393, 107-117. [CrossRef]

22. Ramirez, M.; Pacheco-Londoño, L.; Peña Quevedo, A.; Hernández-Rivera, S. Characterization of peroxide-based explosives by thermal analysis-Art. no. 62012B. Proc. SPIE 2006, 6201, 62012B-620111A. [CrossRef] 
23. Stefanov, A.; Stibor, A.; Dominguez-Clarimon, A.; Arndt, M. Sublimation enthalpy of dye molecules measured using fluorescence. J. Chem. Phys. 2004, 121, 6935-6940. [CrossRef] [PubMed]

24. Mehta, N.; Goenaga-Polo, J.; Hernández-Rivera, S.P.; Hernández, D.; Thomson, M.A.; Melling, P.J. Development of an In-Situ Spectroscopic Method for Cleaning Validation Using Mid-IR Fiber Optics. Spectroscopy 2003, 18, 14 .

25. Hamilton, M.L.; Perston, B.B.; Harland, P.W.; Williamson, B.E.; Thomson, M.A.; Melling, P.J. Grazing-Angle Fiber-Optic IRRAS for in Situ Cleaning Validation. Org. Process Res. Dev. 2005, 9, 337-343. [CrossRef]

26. Primera-Pedrozo, O.; Pacheco-Londono, L.; De la Torre-Quintana, L.; Hernández-Rivera, S.; Thomas Chamberlain, R.; Lareau, R. Use of fiber-optic coupled FT-IR in detection of explosives on surfaces. Proc. SPIE 2004, 5403, 237-245. [CrossRef]

27. Casperson, L.W. Grazing reflection of Gaussian beams. Appl. Opt. 1999, 38, 554-562. [CrossRef] [PubMed]

28. Verdeyen, J.T. Laser Electronics, 1st ed.; Prentice-Hall, Inc.: Upper Saddle River, NJ, USA, 1981.

29. Mansfield, E.; Kar, A.; Quinn, T.P.; Hooker, S.A. Quartz Crystal Microbalances for Microscale Thermogravimetric Analysis. Anal. Chem. 2010, 82, 9977-9982. [CrossRef] [PubMed]

30. Price, D.M. Volatilisation, evaporation and vapour pressure studies using a thermobalance. J. Therm. Anal. Calorim. 2001, 64, 315-322. [CrossRef]

31. Langmuir, I. The vapor pressure of metallic tungsten. Phys. Rev. 1913, 2, 329-342. [CrossRef]

32. Price, D.M.; Hawkins, M. Calorimetry of two disperse dyes using thermogravimetry. Thermochim. Acta 1998, 315, 19-24. [CrossRef]

33. Colomina, M.; Jimenez, P.; Turrion, C. Vapour pressures and enthalpies of sublimation of naphthalene and benzoic acid. J. Chem. Thermodyn. 1982, 14, 779-784. [CrossRef]

34. Ribeiro da Silva, M.A.V.; Monte, M.J.S.; Santos, L.M.N.B.F. The design, construction, and testing of a new Knudsen effusion apparatus. J. Chem. Thermodyn. 2006, 38, 778-787. [CrossRef]

35. Oura, K.; Lifshits, V.G.; Saranin, A.A.; Zotov, A.V.; Katayama, M. Surface Science: An Introduction; Springer: Berlin, Germany, 2003.

36. Redhead, P.A. Thermal desorption of gases. Vacuum 1962, 12, 203-211. [CrossRef]

37. Tolstoy, V.P.; Chernyshova, I.V.; Skryshevsky, V.A. Handbook of Infrared Spectroscopy of Ultrathin Films; Wiley-Interscience: Hoboken, NJ, USA, 2003.

38. Buttigieg, G.A.; Knight, A.K.; Denson, S.; Pommier, C.; Bonner Denton, M. Characterization of the explosive triacetone triperoxide and detection by ion mobility spectrometry. Forensic Sci. Int. 2003, 135, 53-59. [CrossRef]

39. Brauer, B.; Dubnikova, F.; Zeiri, Y.; Kosloff, R.; Gerber, R.B. Vibrational spectroscopy of triacetone triperoxide (TATP): Anharmonic fundamentals, overtones and combination bands. Spectrochim. Acta-Part A Mol. Biomol. Spectrosc. 2008, 71, 1438-1445. [CrossRef] [PubMed]

40. Alzate, L.F.; Ramos, C.M.; Hernandez, N.M.; Hernandez, S.P.; Mina, N. The vibrational spectroscopic signature of TNT in clay minerals. Vib. Spectrosc. 2006, 42, 357-368. [CrossRef]

41. Ortiz-Rivera, W.; Pacheco-Londoño, L.; Castro, J.; Felix-Rivera, H.; Hernendez-Rivera, S. Vibrational Spectroscopy Standoff Detection of Threat Chemicals. Proc. SPIE 2011, 8031, 803129. [CrossRef]

42. Pacheco-Londoño, L.; Ortiz-Rivera, W.; Primera-Pedrozo, O.; Hernandez-Rivera, S. Vibrational spectroscopy standoff detection of explosives. Anal. Bioanal. Chem. 2009, 395, 323-335. [CrossRef]

43. Infante-Castillo, R.; Pacheco-Londoño, L.C.; Hernandez-Rivera, S.P. Monitoring the $\alpha$ to $\beta$ solid-solid phase transition of RDX with Raman spectroscopy: A theoretical and experimental study. J. Mol. Struct. 2010, 970, 51-58. [CrossRef]

44. Infante-Castillo, R.; Pacheco-Londoño, L.; Hernandez-Rivera, S.P. Vibrational spectra and structure of RDX and its 13C- and 15N-labeled derivatives: A theoretical and experimental study. Spectrochim. Acta Part A Mol. Biomol. Spectrosc. 2010, 76, 137-141. [CrossRef]

45. Torres, P.; Mercado, L.; Cotte, I.; Hernandez, S.P.; Mina, N.; Santana, A.; Chamberlain, R.T.; Lareau, R.; Castro, M.E. Vibrational Spectroscopy Study of $\beta$ and $\alpha$ RDX Deposits. J. Phys. Chem. B 2004, 108, 8799-8805. [CrossRef]

46. Figueroa-Navedo, A.M.; Ruiz-Caballero, J.L.; Pacheco-Londoño, L.C.; Hernandez-Rivera, S.P. Characterization of $\alpha$ - and $\beta$-RDX Polymorphs in Crystalline Deposits on Stainless Steel Substrates. Cryst. Growth Des. 2016, 16, 3631-3638. [CrossRef] 
47. Ruiz-Caballero, J.L.; Aparicio-Bolaño, J.A.; Figueroa-Navedo, A.M.; Pacheco-Londoño, L.C.; Hernandez-Rivera, S.P. Optical Properties of $\beta$-RDX Thin Films Deposited on Gold and Stainless Steel Substrates Calculated from Reflection-Absorption Infrared Spectra. Appl. Spectrosc. 2017, 71, 1990-2000. [CrossRef] [PubMed]

48. Ruiz-Caballero, J.L.; Blanco-Riveiro, L.A.; Ramirez-Marrero, I.A.; Perez-Almodovar, L.A.; Colon-Mercado, A.M.; Castro-Suarez, J.R.; Pacheco-Londoño, L.C.; Hernandez-Rivera, S.P. Enhanced RDX Detection Studies on Various Types of Substrates via Tunable Quantum Cascade Laser Spectrometer Coupled with Grazing Angle Probe. IOP Conf. Ser. Mater. Sci. Eng. 2019, 519, 012007. [CrossRef]

49. Wold, S.; Sjöströma, M.; Eriksson, L. PLS-regression: A basic tool of chemometrics. Chemom. Intell. Lab. Syst. 2001, 58, 109-130. [CrossRef]

50. Mardia, J.K.V.; Kent, J.T.; Biby, J.M. Chemometrics: Statistic and Computer Application in Analytical Chemistry; Academic Press: London, UK, 1980.

51. Otto, M. Chemometrics: Statistic and Computer Application in Analytical Chemistry; Wiley-VCH: Weinheim, Germany, 1999.

52. Brereton. Chemometrics: Data Analysis for the Laboratory and Chemical Plant; John Wiley \& Sons, Ltd: Chichester, UK, 2003.

53. Beebe, K.R.; Pell, R.J.; Seasholtz, M.B. Chemometrics. A Pactricla Guide; John Wiley \& Sons, Inc: New York, NY, USA, 1998.

54. Primera-Pedrozo, O.; Soto-Feliciano, Y.; Pacheco-Londoño, L.; Hernandez-Rivera, S. Detection of High Explosives Using Reflection Absorption Infrared Spectroscopy with Fiber Coupled Grazing Angle Probe/FTIR. Sens. Imaging Int. J. 2009, 10, 1-13. [CrossRef]

55. Primera-Pedrozo, O.; Soto-Feliciano, Y.; Pacheco-Londoño, L.; Hernandez-Rivera, S. High Explosives Mixtures Detection Using Fiber Optics Coupled: Grazing Angle Probe/Fourier Transform Reflection Absorption Infrared Spectroscopy. Sens. Imaging Int. J. 2008, 9, 27-40. [CrossRef]

56. Galán-Freyle, N.J.; Pacheco-Londoño, L.C.; Figueroa-Navedo, A.M.; Hernandez-Rivera, S.P. Standoff Detection of Highly Energetic Materials Using Laser-Induced Thermal Excitation of Infrared Emission. Appl. Spectrosc. 2015, 69, 535-544. [CrossRef]

57. Wrable-Rose, M.; Primera-Pedrozo, O.M.; Pacheco-Londoño, L.C.; Hernandez-Rivera, S.P. Preparation of TNT, RDX and ammonium nitrate standards on gold-on-silicon surfaces by thermal inkjet technology. Sens. Imaging 2010, 11, 147-169. [CrossRef]

58. Thumanu, K.; Tanthanuch, W.; Lorthongpanich, C.; Heraud, P.; Parnpai, R. FTIR microspectroscopic imaging as a new tool to distinguish chemical composition of mouse blastocyst. J. Mol. Struct. 2009, 933, 104-111. [CrossRef]

59. Faber, N.M.; Bro, R. Standard error of prediction for multiway PLS-1. Background and a simulation study. Chemom. Intell. Lab. Syst. 2002, 61, 133-149. [CrossRef]

60. Felipe-Sotelo, M.; Cal-Prieto, M.J.; Ferre, J.; Boque, R.; Andrade, J.M.; Carlosena, A. Linear PLS regression to cope with interferences of major concomitants in the determination of antimony by ETAAS. J. Anal. At. Spectrom. 2006, 21, 61-68. [CrossRef]

61. Galan-Freyle, N.J.; Pacheco-Londoño, L.C.; Roman-Ospino, A.D.; Hernandez-Rivera, S.P. Applications of Quantum Cascade Laser Spectroscopy in the Analysis of Pharmaceutical Formulations. Appl. Spectrosc. 2016, 70, 1511-1519. [CrossRef]

62. Pacheco-Londoño, L.C.; Galán-Freyle, N.J.; Figueroa-Navedo, A.M.; Infante-Castillo, R.; Ruiz-Caballero, J.L.; Hernández-Rivera, S.P. Quantum cascade laser back-reflection spectroscopy at grazing-angle incidence using the fast Fourier transform as a data preprocessing algorithm. J. Chemom. 2019, 33, e3167. [CrossRef]

63. Pacheco-Londoño, L.C.; Aparicio-Bolaño, J.A.; Galan-Freyle, N.J.; Roman-Ospino, A.D.; Ruiz-Caballero, J.L.; Hernandez-Rivera, S.P. Classical Least Squares-Assisted Mid-Infrared (MIR) Laser Spectroscopy Detection of High Explosives on Fabrics. Appl. Spectrosc. 2019, 73, 17-29. [CrossRef]

64. IUPAC. Erratum: International union of pure and applied chemistry analytical chemistry division commission on spectrochemical and other optical procedures for analysis nomenclature, symbols, units and their usage in spectrochemical analysis - II. Data interpretation (Analytical Chemistry (1976) 48 (1424)). Anal. Chem. 1976, 48, 2293.

65. Goldberg, I.G.; Swift, J.A. New Insights into the Metastable $\beta$ Form of RDX. Cryst. Growth Des. 2012, 12, 1040-1045. [CrossRef] 
66. Verevkin, S.P. Enthalpy of sublimation of dibenzofuran: A redetermination. Phys. Chem. Chem. Phys. 2003, 5, 710-712. [CrossRef]

67. Bevington, P.R.; Robinson, D.K. Data Reduction and Error Analysis for the Physical Sciences, 3rd ed.; McGraw-Hill: New York, NY, USA, 2003.

68. Hibbert, D.B. The uncertainty of a result from a linear calibration. Analyst 2006, 131, 1273-1278. [CrossRef]

69. Damour, P.L.; Freedman, A.; Wormhoudt, J. Knudsen Effusion Measurement of Organic Peroxide Vapor Pressures. Propellants Explos. Pyrotech. 2010, 35, 514-520. [CrossRef]

70. Felix-Rivera, H.; Ramirez-Cedeño, M.L.; Sanchez-Cuprill, R.A.; Hernandez-Rivera, S.P. Triacetone triperoxide thermogravimetric study of vapor pressure and enthalpy of sublimation in 303-338 K temperature range. Thermochim. Acta 2011, 514, 37-43. [CrossRef]

71. Oxley, J.C.; Smith, J.L.; Shinde, K.; Moran, J. Determination of the Vapor Density of Triacetone Triperoxide (TATP) Using a Gas Chromatography Headspace Technique. Propellants Explos. Pyrotech. 2005, 30, 127-130. [CrossRef]

72. Oxley, J.C.; Smith, J.L.; Luo, W.; Brady, J. Determining the Vapor Pressures of Diacetone Diperoxide (DADP) and Hexamethylene Triperoxide Diamine (HMTD). Propellants Explos. Pyrotech. 2009, 34, 539-543. [CrossRef]

73. Dunayevskiy, I.; Tsekoun, A.; Prasanna, M.; Go, R.; Patel, C.K.N. High-sensitivity detection of triacetone triperoxide (TATP) and its precursor acetone. Appl. Opt. 2007, 46, 6397-6404. [CrossRef] [PubMed]

74. Espinosa-Fuentes, E.; Castro-Suarez, J.; Meza-Payares, D.; Pacheco-Londono, L.; Hernández-Rivera, S. Sublimation enthalpy of homemade peroxide explosives using a theoretically supported nonlinear equation. J. Therm. Anal. Calorim. 2015, 119, 681-688. [CrossRef]

75. Harris, N.J.; Lammertsma, K. Ab Initio Density Functional Computations of Conformations and Bond Dissociation Energies for Hexahydro-1,3,5-trinitro-1,3,5-triazine. J. Am. Chem. Soc. 1997, 119, 6583-6589. [CrossRef]

76. Rice, B.M.; Chabalowski, C.F. Ab Initio and Nonlocal Density Functional Study of 1,3,5-Trinitro-s-triazine (RDX) Conformers. J. Phys. Chem. A 1997, 101, 8720-8726. [CrossRef]

77. Vladimiroff, T.; Rice, B.M. Reinvestigation of the Gas-Phase Structure of RDX Using Density Functional Theory Predictions of Electron-Scattering Intensities. J. Phys. Chem. A 2002, 106, 10437-10443. [CrossRef]

78. Lenchitz, C.; Velicky, R.W. Vapor pressure and heat of sublimation of three nitrotoluenes. J. Chem. Eng. Data 1970, 15, 401-403. [CrossRef]

79. Pella, P.A. Generator for producing trace vapor concentrations of 2,4,6-trinitrotoluene, 2,4-dinitrotoluene, and ethylene glycol dinitrate for calibrating explosives vapor detectors. Anal. Chem. 1976, 48, 1632-1637. [CrossRef]

80. Lenchitz, C.; Velicky, R.W.; Silvestro, G.; Schlosberg, L.P. Thermodynamic properties of several nitrotoluenes. J. Chem. Thermodyn. 1971, 3, 689-692. [CrossRef]

81. Edwards, G. The vapour pressure of $2: 4:$ 6-trinitrotoluene. Trans. Faraday Soc. 1950, 46, 423-427. [CrossRef]

82. Dionne, B.C.; Rounbehler, D.P.; Achter, E.K.; Hobbs, J.R.; Fine, D.H. Vapor pressure of explosives. J. Energ. Mater. 1986, 4, 447-472. [CrossRef]

83. Gershanik, A.P.; Zeiri, Y. Sublimation Rate of TNT Microcrystals in Air. J. Phys. Chem. A 2010, 114, 12403-12410. [CrossRef] [PubMed]

84. Eiceman, G.A.; Preston, D.; Tiano, G.; Rodriguez, J.; Parmeter, J.E. Quantitative calibration of vapor levels of TNT, RDX, and PETN using a diffusion generator with gravimetry and ion mobility spectrometry. Talanta 1997, 45, 57-74. [CrossRef]

85. Leggett, D.C. Vapor pressure of 2,4,6-trinitrotoluene by a gas chromatographic headspace technique. J. Chromatogr. A 1977, 133, 83-90. [CrossRef]

86. Hikal, W.M.; Weeks, B.L. Sublimation kinetics and diffusion coefficients of TNT, PETN, and RDX in air by thermogravimetry. Talanta 2014, 125, 24-28. [CrossRef]

87. Hikal, W.M.; Paden, J.T.; Weeks, B.L. Thermo-optical determination of vapor pressures of TNT and RDX nanofilms. Talanta 2011, 87, 290-294. [CrossRef]

88. Mu, R.; Ueda, A.; Liu, Y.C.; Wu, M.; Henderson, D.O.; Lareau, R.T.; Chamberlain, R.T. Effects of interfacial interaction potential on the sublimation rates of TNT films on a silica surface examined by QCM and AFM techniques. Surf. Sci. 2003, 530, L293-L296. [CrossRef]

89. Chickos, J.S.; Acree, W.E. Enthalpies of Sublimation of Organic and Organometallic Compounds. 1910-2001. J. Phys. Chem. Ref. Data 2002, 31, 537-698. [CrossRef] 
90. Cundall, R.B.; Frank Palmer, T.; Wood, C.E.C. Vapour pressure measurements on some organic high explosives. J. Chem. Soc. Faraday Trans. 1 Phys. Chem. Condens. Phases 1978, 74, 1339-1345. [CrossRef]

91. Pella, P.A. Measurement of the vapor pressures of tnt, 2,4-dnt, 2,6-dnt, and egdn. J. Chem. Thermodyn. 1977, 9, 301-305. [CrossRef]

92. Jones, A.H. Sublimation Pressure Data for Organic Compounds. J. Chem. Eng. Data 1960, 5, 196-200. [CrossRef]

93. Hikal, W.M.; Weeks, B.L. Non-Isothermal Sublimation Kinetics of 2,4,6-Trinitrotoluene (TNT) Nanofilms. Molecules 2019, 24, 1163. [CrossRef] [PubMed]

94. Lee, Y.J.; Weeks, B.L. Investigation of Size-Dependent Sublimation Kinetics of 2,4,6-Trinitrotoluene (TNT) Micro-Islands Using In Situ Atomic Force Microscopy. Molecules 2019, 24, 1895. [CrossRef] [PubMed]

95. Rosen, J.M.; Dickinson, C. Vapor pressures and heats of sublimation of some high-melting organic explosives. J. Chem. Eng. Data 1969, 14, 120-124. [CrossRef]

96. Gershanik, A.P.; Zeiri, Y. Sublimation Rate of Energetic Materials in Air: RDX and PETN. Propellants Explos. Pyrotech. 2012, 37, 207-214. [CrossRef]

Sample Availability: Not available.

(C) 2019 by the authors. Licensee MDPI, Basel, Switzerland. This article is an open access article distributed under the terms and conditions of the Creative Commons Attribution (CC BY) license (http://creativecommons.org/licenses/by/4.0/). 